\title{
Numerical modelling of sedimentary structures in rivers on Earth and Titan
}

\author{
Katarzyna MISIURA ${ }^{1, *}$ and Leszek CZECHOWSKI ${ }^{1}$ \\ 1 University of Warsaw, Department of Physics, Institute of Geophysics, Pasteura 7, 02-093 Warszawa, Poland
}

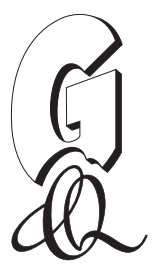

Misiura, K., Czechowski, L., 2015. Numerical modelling of sedimentary structures in rivers on Earth and Titan. Geological Quarterly, 59 (3): 565-580, doi: 10.7306/gq.1236

\begin{abstract}
The differences in the evolution of rivers on Earth and on Titan are investigated. Dynamical analysis of the rivers was performed using a numerical package CCHE2D developed by the National Center for Computational Hydroscience and Engineering, University of Mississippi. The model is based on the Navier-Stokes equations for depth-integrated two-dimensional turbulent flow and the three-dimensional convection-diffusion equation of sediment transport. The model enables investigation of the evolution of rivers as a function of total discharge and other parameters of the river. Series of short (from one to several hours) and long (up to 67 days) simulations were performed. We have found that three different liquid hydrocarbons considered for Titan's rivers give similar velocity fields. It was also found that the suspended load is the main means of transport in Titan's rivers, while in terrestrial ones, for the same discharge, the bedload could be of the same order as suspended load. Moreover, we suppose that for specific boundary conditions, the evolution of rivers on the Earth promotes the development of braided rivers, while for the same conditions evolution on Titan favours regular meandering rivers.
\end{abstract}

Key words: Titan, Earth, meandering river, erosion, sedimentation.

\section{INTRODUCTION}

Our knowledge about Titan increased substantially since 2004 when the spacecraft Cassini reached the Saturnian System and the probe Huygens landed on the surface of this satellite. On Titan, there is not liquid water on the surface, but liquid methane and other hydrocarbons. Water ice is the main component of the surface Titanian rocks and of its regolith (Tomasko et al., 2005), i.e. its role is similar to that of the silicates and other rocks on Earth. Moreover, the CassiniHuygens mission indicates the existence of a methane cycle analogical to the terrestrial hydrologic cycle. Therefore, we can assume that the surface of Titan is shaped by analogous (e.g., aeolian, fluvial) processes like on Earth. These processes form similar types of geomorphologic features, such as dunes, river valley, lakes, and so on (Lunine and Lorenz, 2009). The radar images sent by Cassini show a number of such features recognized on the basis of different radar albedo and topography (Barnes et al., 2007; Lorenz et al., 2008).

Most of the data used here are from the Cassini systems: RADAR (radar in $13.76 \mathrm{GHz}$ ), ISS (cameras of the Imaging Science Subsystem), and VIMS (Visible and Infrared Mapping Spectrometer). The present resolution of the global maps of Titan is too low to determine many details of river valley morphology (VIMS and ISS data - a few km/pixel, RADAR data - from

\footnotetext{
* Corresponding author, e-mail: Katarzyna.Misiura@fuw.edu.pl
}

Received: January 21, 2014; accepted: April 15, 2015; first published online: June 29, 2015
$350 \mathrm{~m} /$ pixel to $1.7 \mathrm{~km} /$ pixel - e.g., Burr et al., 2013b). However, the resolution is good enough to recognize the general pattern of well-developed river valleys and large depositional bodies (e.g., alluvial fans). The characteristic time of evolution of a given river's feature varies from days to dozens of years, and depends on the discharge and other parameters, including lithology and erodibility; for example, during flooding the change of meander is faster. Because precipitation depends on season, it is still possible that significant changes of some river valleys will be observed during the Cassini mission.

The models of Titan's rivers could help with understanding their evolution. Note that the rate of evolution depends also on features not observable by Cassini, e.g. details of topography of a channel bed, size and distribution of deposits, discharge, and its temporal changes and so on. Understanding their roles in evolution would make it possible to determine at least some of these unobservable features. For example, consider D50. The sense of $D 50$ is that the total mass of grains smaller than $D 50$ is equal to half of the total mass. The knowledge of the role of $D 50$ of any grain distributions (bedload, suspended load or bed sediments) will help to determine the value of $D 50$ from the Cassini observation of the rate of channel changes. Note that the lack of visible changes after heavy precipitation also gives some limits for unobservable parameters. Concluding, we hope that numerical models of Titan's rivers will help to determine some important parameters of the rivers and to understand their evolution. This is the aim of our research.

Meandering-like channels are observed for various conditions. They are observed on the surface of Mars (e.g., Carr and Clow, 1981) where the density and the gravity are different than on Earth. Martian rivers show many similar geomorphological features to terrestrial ones, indicating similar interactions with 
the Martian environment (e.g., Craddock and Maxwell, 1993). Carved riverbeds and valleys have been observed, including islands (Baker and Kochel, 1979), curvatures, and characteristic valley shapes (e.g., Kereszturi 2003, 2005). Moreover, such channels are found on the oceanic floor of Earth (Abad et al., 2010; Sequeiros et al., 2010). Meandering channels could also be a result of lava flow, e.g. on the Moon (Hulme, 1973). Therefore, we believe that our investigations could have some value not only for understanding processes on Titan but also for general knowledge of fluvial processes.

There are several interesting publications regarding Titanian rivers (e.g., Tomasko et al., 2005; Burr et al., 2006; Lorenz et al., 2008; Lunine and Lorenz, 2009; Langhans et al., 2012); they are discussed in the text. However, according to our best knowledge, our research is the first model of fluvial processes on Titan using a dynamical model based on physical equations of motion, continuity, and sedimentation. The present paper is an extension of the conference presentation of Misiura and Czechowski (2013). Witek and Czechowski (2015) presented similar research concerning the evolution of river deltas.

\section{GENERAL INFORMATION ABOUT RIVERS}

The flow of liquid on the surface of a planet results in various forms of accumulation and erosional features found in river valleys. Their formation depends on the type of flow, properties of the liquid, method of transport, and characteristics of the transported material.

Generally, accumulation and erosion change in a dynamic way, both in temporal and spatial aspects. The main subjects of this research are the river valleys, where accumulation domi- nates over erosion. We choose this type of river because accumulation is easier to recognize by remote sensing than by erosion. If we know the processes forming valleys on Earth, we could - by analogy - discover what kind of processes operate on Titan.

The typical terrestrial lowland river valley, where accumulation dominates over erosion, has the following basic elements: a riverbed, a floodplain, and a fluvial terrace (or terraces). A well-developed lowland river valley, especially a meandering river, has:

- a few terraces;

- a floodplain with structures indicating past flooding (e.g., broken levees, crevasses);

- signs of continuous changes of channel position (e.g., oxbow lakes and bogs in old river beds);

- the channel's sedimentary structures (different examples of point bars).

We distinguish a few different types of river, depending on the chosen criteria. According to the channel sinuosity, the number of channels, and their lateral migration, one can distinguish the following types of river: straight, meandering, braided, and anastomosing (Fig. 1).

Our numerical model could be used for any river type, however, the time that would be required for a comprehensive modelling of all the river types is outside the possibility of this research. Therefore, in this study, we focus on the channels of simple morphology, i.e. meandering rivers. We explore sediment transport in a river channel under conditions relevant to Titan and we compare them with similar models in terrestrial conditions. The knowledge of the terrestrial processes and their differences compared to Titan will enable us to infer the analogous processes on Titan.

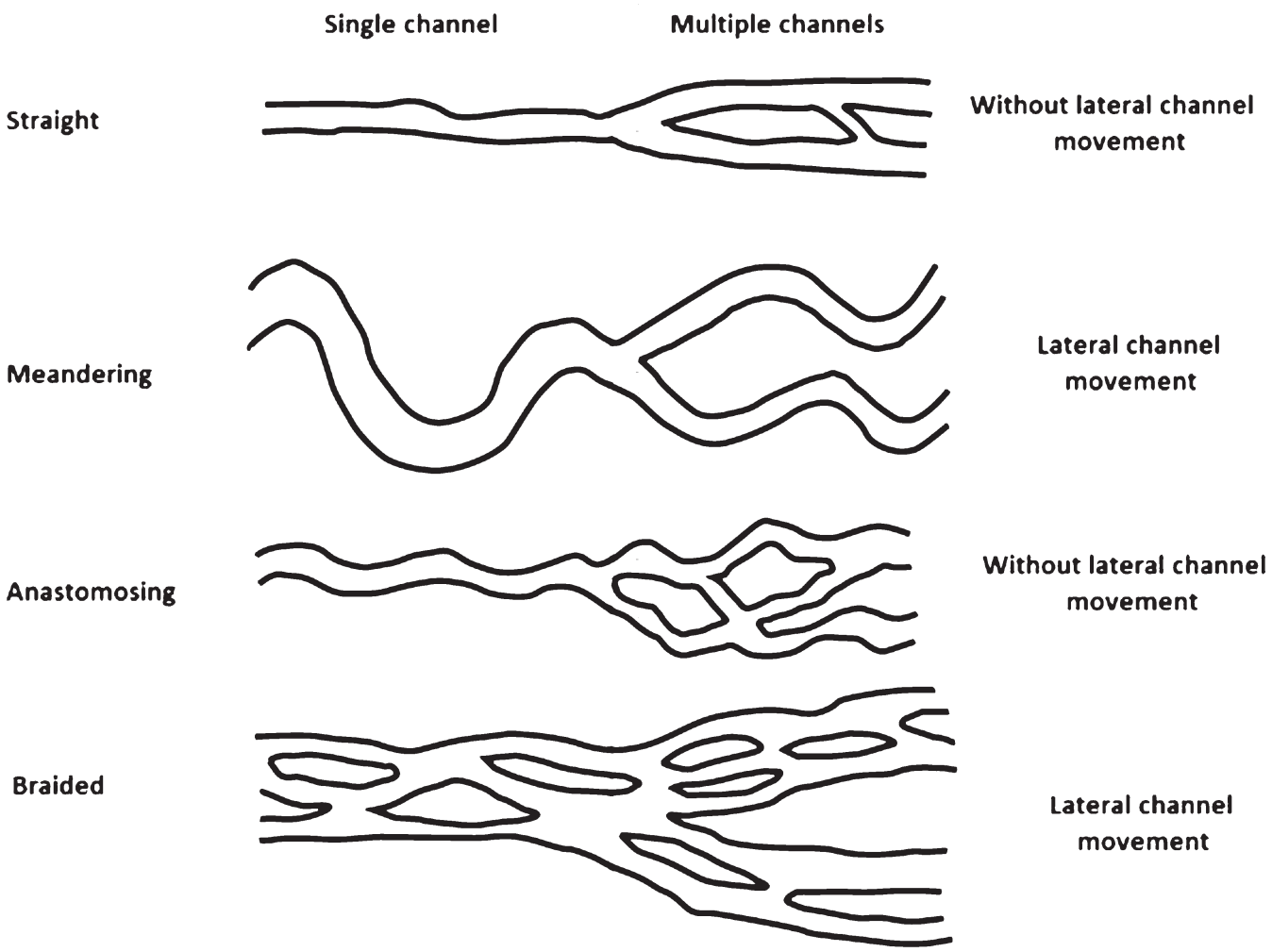

Fig. 1. River types based on their sinuosity, number of channels and lateral movement (based on Schumm, 1981; Nichols, 1999) 


\section{BASIC INFORMATION ABOUT TITAN}

Titan is the largest moon of Saturn and the second largest moon in the Solar System. It is the only celestial body, besides Earth, where current $\mathrm{p}-\mathrm{T}$ conditions allow for the permanent presence of liquid on its solid surface. The average surface temperature on Titan is $\sim 93.7 \mathrm{~K}$ and the average surface pressure is $\sim 1496 \mathrm{hPa}$ (Atreya et al., 2009). Titan's surface liquids are composed mostly of nitrogen and light hydrocarbons (i.e. methane, ethane). They form a number of lakes and rivers, usually in the polar regions (Hayes et al., 2008; Lopes et al., 2010; Moore and Howard, 2010; Langhans et al., 2012; Burr et al., 2013b).

The Titan year lasts 29,423 terrestrial years, which is equal to the orbital period of Saturn. The inclination of Titan's rotational axis with respect to the plane of Saturn's orbit is similar to the terrestrial inclination axis with respect to the plane of the ecliptic $\left(26.7^{\circ}\right.$ versus $\left.23.45^{\circ}\right)$. Therefore, the distribution of climatic regions and seasonal changes on Titan are similar to terrestrial ones.

Pictures from the Cassini mission made in 2007 during winter on the northern hemisphere indicate the existence of lakes and seas. Some of them are very large (e.g., Kraken Mare $\sim 400000 \mathrm{~km}^{2}$, Ligeia Mare $\sim 100000 \mathrm{~km}^{2}$ ). At the same time, lakes observed on the southern hemisphere were smaller. However, some observations indicate that these lakes were larger in the past (Moore and Howard, 2010; Turtle et al., 2011a). This fact could be explained by a lower temperature on the winter northern hemisphere (condensation and precipitation are expected in regions of low temperature - Langhans et al., 2012).

Since 2004, when the Cassini probe reached Saturn's system, the surface of Titan has been observed several times every terrestrial year. Our discussion is based on the interpretation of data by other scientists. We present a short summary of their conclusions only. Comparison of the radar pictures acquired for different times indicates that the sizes of some lakes are changing (Mitri et al., 2007). Moreover, it is also found that the surface of Ontario Lacus changed its brightness between consecutive observations. These changes of size and brightness of the dark area could be explained as a result of evaporation (e.g., Cornet et al., 2012). Note that "brightness" or "albedo" often refer to results of RADAR data. There are also observations of the opposite process, for condensation. This can be linked with observations of clouds in the southern polar region. The disappearance of these clouds coincided with the decreasing albedo of the surface (Turtle et al., 2011b). This phenomenon could be explained as a result of intense precipitation, which leads to wetting/moistening of the surface. It could be treated as proof of existence of a methane cycle on Titan (Griffith et al., 2000; Lunine and Atreya, 2008), analogous to the terrestrial hydrological cycle (Atreya et al., 2009).

The methane cycle can be described in the following way: methane causes a noticeable part of Titan's atmosphere to form clouds at the cold polar region. Later, in the form of the rain, it reaches the moon's surface (Jaumann et al., 2008). Next, the liquid, according to gravity, flows from an upper to a lower region, eventually forming streams, rivers, and lakes (Lunine and Lorenz, 2009). During runoff, the liquid could infiltrate the regolith and form "groundwater" (Tomasko et al., 2005; Czechowski and Kossacki, 2012).
For numerical simulations we use the package CCHE2D developed by the National Center for Computational Hydroscience and Engineering (University of Mississippi), adapted for the specific conditions on Titan (Wu, 2001; Zhang, 2006). The package solves the Navier-Stokes equations for depth-integrated two-dimensional turbulent flow and the three-dimensional convection-diffusion equation of sediment transport (Jia and Wang, 2001).

\section{CHARACTERISTICS OF THE RIVERS STUDIED}

\section{EAST FORK RIVER}

For our simulations we used some Earth analogue data concerning East Fork River (Fig. 2). This river is situated in Wyoming (USA); its total length is approximately $72 \mathrm{~km}$. It is a tributary of New Fork River and is oriented south-west. In our model we consider its $2 \mathrm{~km}$ section (Fig. 3). In the model we use the topography of the river bed given by Wu (2001), Jia and Wang (2001), and Zhang (2006). We chose this particular geometry as an example of a meandering river with a well-developed river bed. Note that starting from the natural initial topography has some advantages because in an artificial channel some transient artificial phenomena could be stronger. We want to concentrate on the physical conditions of simulations, so we use the same geometry for terrestrial and Titan's models. In fact, we don't know the geometry of any of Titan's rivers, so the use of a terrestrial one is justified. Note that the present resolution of Titan pictures is not good enough to determine the channel courses of Titan's rivers; we know only the course of their valleys.

Below we describe the topography of the chosen fragment of the river bed. The lowest point of its topography is on the level

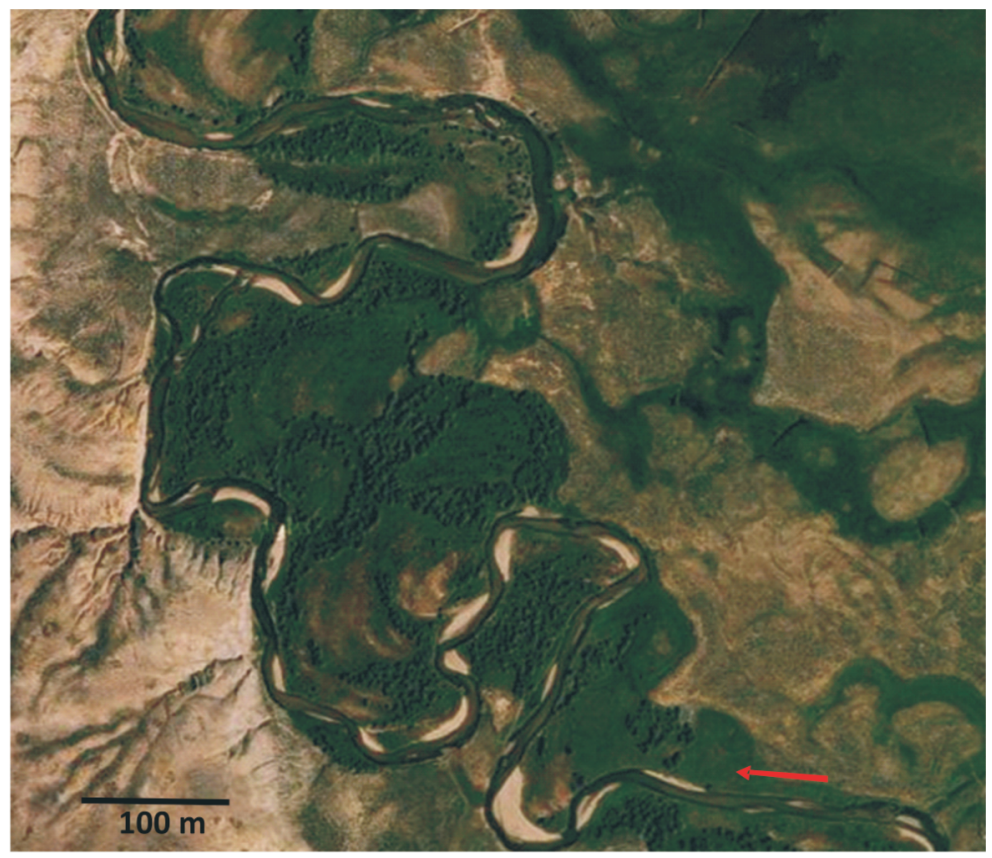

Fig. 2. The section of East Fork River used in our simulations photography of the river by Google Maps

Red arrow indicates the direction of flow in the river 


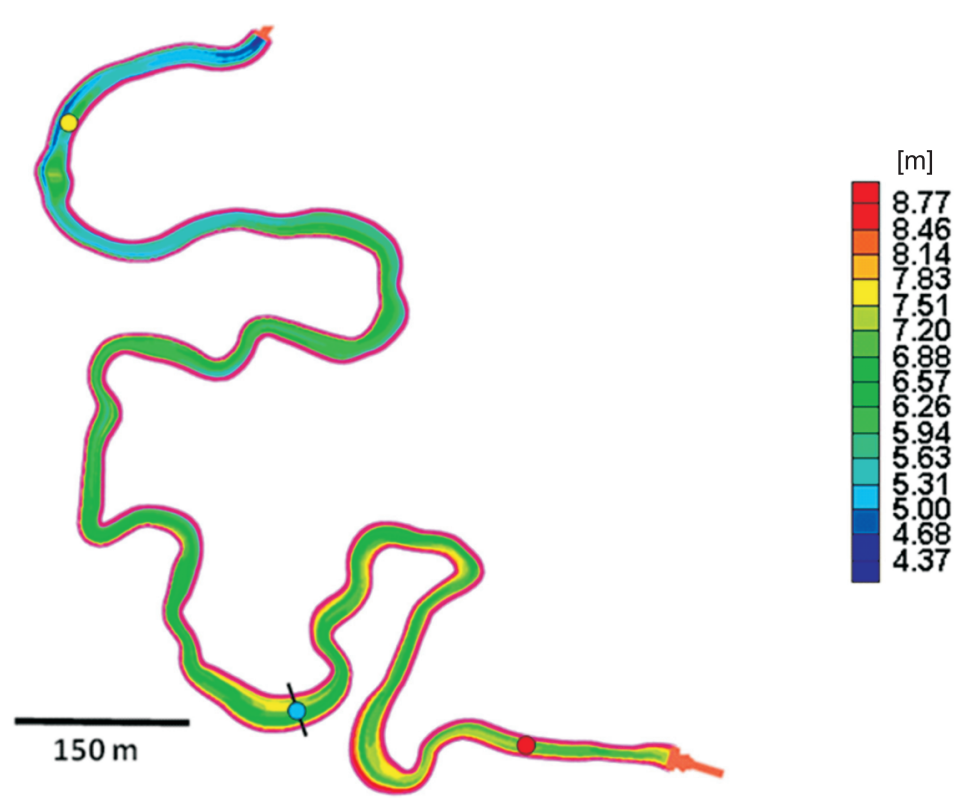

Fig. 3. Initial topography of the bed of East Fork River used in simulations

Topography is given with respect to the chosen frame of reference; dots mark approximate places of mesh nodes: no. 886 - red, no. 5620, 5633 and 5728 blue, no. 15084 - yellow; thick, black line marks cross-section $J=172$ discussed in Figure 14

of $4.37 \mathrm{~m}$ (river bed in the lower course) with respect to the chosen frame of reference, and the highest point is on the level $8.77 \mathrm{~m}$ (bank of the upper course; Fig. 3). In short simulations (from one to several hours) we assume hydraulic head as $1 \mathrm{~m}$ and in long simulations as $2 \mathrm{~m}$ - these are the lowest hydraulic heads for which simulations proceed quickly enough. The initial water surface changes linearly for long simulations from $7.5 \mathrm{~m}$ (on the inflow) to $5.5 \mathrm{~m}$ (on the outflow), and for short simulations from 8-10 and $11 \mathrm{~m}$ (on the inflow) to 7-9 and $10 \mathrm{~m}$, respectively (on the outflow). The Manning coefficient, determining the roughness of the bed, is chosen as 0.03 for the whole riverbed, because a similar value is usually used for terrestrial channels filled with coarse sand (Jaromin et al., 2008; Arcement and Schneider, 2013). In our simulation we also used mainly coarse sand.

In our work we performed two types of simulations: short (from one to several hours) and long (from one day to 67 days). The basic parameters of the river used for long simulations, which could be controlled by the user, are shown in Table 1 . Other parameters are discussed further in the text.

\section{RIVERS ON TITAN}

On Titan there are many river valleys. They have either high radar brightness (probably presently dry river beds) or low brightness (probably with some liquid hydrocarbons) (Lorenz et al., 2008; LeGall et al., 2010; Langhans et al., 2012; Burr et al., $2013 a, b)$. They are placed in many regions, e.g. Shangri-La (landing place of the Huygens; Fig. 4; Langhans et al., 2012; Burr et al., 2013b), in both of the polar regions, and in the Xanadu region (i.e. an equatorial region; Fig. 5). Some of these river valleys have tributary systems (Tomasko et al., 2005; Soderblom et al., 2007), although besides the polar region, they are probably dry under the current climate (Kereszturi, 2010).

\section{MATERIAL PROPERTIES}

\section{PROPERTIES OF LIQUIDS}

Consider now the liquids flowing on Earth and on Titan (Cordier et al., 2009; Lorenz et al., 2010; Czechowski and Kossacki, 2012). The water is the liquid in terrestrial rivers; its parameters are given in Table 2.

For Titan we have a slightly more complicated situation. At least 5 different liquids are considered (Lunine and Atreya, 2008; Atreya et al., 2009; Strobel et al., 2009; Cordier et al., 2009; Czechowski and Kossacki, 2009, 2012; Lorenz et al., 2010). They are mixtures of light hydrocarbons (methane, ethane, propane) and nitrogen N2 (Table 2). The following compositions are the most probable:

- $75 \%$ methane $+25 \%$ nitrogen - corresponding to Titan's rain;

- $74 \%$ ethane $+10 \%$ methane $+8.5 \%$ butane + $7 \%$ propane $+0.5 \%$ nitrogen - corresponding to the liquids of the lakes;

- $100 \%$ methane.

This uncertainty is a result of changing compositions during the methane cycle, e.g. the initial composition is changing as a result of evaporation (Lunine and Atreya, 2008; Atreya et al., 2009). This could cause problems for simulations because simulations should be performed with all liquids. Fortunately, our preliminary calculations give similar velocity fields for all the liquids mentioned (e.g., Fig. 6). Therefore, for later calculations we choose one liquid only that corresponds to the expected composition of rains on Titan (Perron et al., 2006; Strobel et al., 2009).

\section{PROPERTIES OF SOLIDS}

Below, the parameters of the transported material are considered. It is difficult to select the particle size distribution as we do not have enough information concerning the regolith of Titan, so we choose sand and fine gravel which are easily transported by a river. These fractions are found in most of the meandering rivers on Earth. Note that most of our calculations are for such rivers. Because of the lack of specific information about rivers on Titan, we used the same grain-size distribution for Titan as for Earth, as mentioned before. We used a modified distribution of Leopold and Emmett (1976) for grain-size distribution. Table 3 shows the granulometric composition that they proposed.

For Wisła River, the authors of numerical package CCHE2D (Wu, 2001; Jia and Wang, 2001; Zhang, 2006) used finer fractions. Note that photos made during the landing of the Huygens probe indicates the existence of large stones (up to $\sim 15 \mathrm{~cm}$ in size) on the bed of the dry lake (e.g., Tomasko et al., 2005). Eventually, following these three suggestions, we used grain-size distribution in the bed of the considered section of the river given in Table 4. This distribution results in fast erosion and sedimentation (important because of the limited speed of simulation), and corresponds to the grain distribution in the bed of meandering rivers. The same distributions are used for bedload and suspended loads at the inflow. The choice of distributions at the inflow is not crucial because "natural" distributions (i.e. distributions corresponding to current velocity fields) will be established in a few tens of metres from the beginning of the section of the 
The list of long simulations (total 18) and values of basic parameters

\begin{tabular}{|c|c|c|c|c|c|}
\hline Model & $\begin{array}{c}\text { Discharge } Q \\
{\left[\mathrm{~m}^{3} \cdot \mathrm{s}^{-1}\right]}\end{array}$ & $\begin{array}{c}\text { Bedload } \\
\text { transport, rate } B \\
{\left[\mathrm{~kg} \cdot \mathrm{m}^{-1} \cdot \mathrm{s}^{-1}\right]}\end{array}$ & $\begin{array}{c}\text { Suspended load } \\
\text { concentration } S \\
{\left[\mathrm{~kg} \cdot \mathrm{m}^{-3}\right]}\end{array}$ & $\begin{array}{l}\text { Thickness of each } \\
\text { of three layers forming } \\
\text { the river bed [m] }\end{array}$ & $\begin{array}{c}\text { Time } \\
\text { of simulations } \\
t_{\text {sim }}\end{array}$ \\
\hline 1T & 20 & 0 & 0 & 0.05 & 50 d 12 h $30 \mathrm{~m}$ \\
\hline $1 Z$ & 20 & 0 & 0 & 0.05 & 54 d 6 h $13 m$ \\
\hline 1T_2 & 20 & 1.0 & 0.5 & 0.05 & 22 d 15 h $46 m$ \\
\hline $1 Z \_2$ & 20 & 1.0 & 0.5 & 0.05 & $24 \mathrm{~d} 13 \mathrm{~h} 25 \mathrm{~m}$ \\
\hline 1T_3 & 20 & 0.5 & 1.0 & 0.05 & $37 \mathrm{~d} 23 \mathrm{~h} 11 \mathrm{~m}$ \\
\hline 1Z_3 & 20 & 0.5 & 1.0 & 0.05 & 37 d 5 h $17 m$ \\
\hline EF_T & 40 & 0 & 0 & 0.05 & $30 \mathrm{~d} 17 \mathrm{~h} 46 \mathrm{~m}$ \\
\hline$E F \_Z$ & 40 & 0 & 0 & 0.05 & 30 d 8 h $48 m$ \\
\hline 1T_6 & 40 & 1.0 & 0.5 & 0.05 & 66 d 22 h $29 \mathrm{~m}$ \\
\hline $1 Z \_6$ & 40 & 1.0 & 0.5 & 0.05 & $66 \mathrm{~d} 16 \mathrm{~h} 24 \mathrm{~m}$ \\
\hline 1T_7 & 40 & 0.5 & 1.0 & 0.05 & $25 \mathrm{~d} 20 \mathrm{~h} 41 \mathrm{~m}$ \\
\hline $1 Z_{-} 7$ & 40 & 0.5 & 1.0 & 0.05 & $26 \mathrm{~d} 10 \mathrm{~h} 4 \mathrm{~m}$ \\
\hline 1T_9 & 40 & 0 & 0 & $0.5,1.0,1.5$ & $37 \mathrm{~d} 14 \mathrm{~h} 11 \mathrm{~m}$ \\
\hline 1Z_9 & 40 & 0 & 0 & $0.5,1.0,1.5$ & $37 \mathrm{~d} 14 \mathrm{~h} 11 \mathrm{~m}$ \\
\hline 1T_10 & 40 & 1.0 & 0.5 & $0.5,1.0,1.5$ & 54 d 6 h $43 m$ \\
\hline 1Z_10 & 40 & 1.0 & 0.5 & $0.5,1.0,1.5$ & 54 d 6 h $46 m$ \\
\hline 1T_11 & 40 & 0.5 & 1.0 & $0.5,1.0,1.5$ & 29 d 5 h $55 \mathrm{~m}$ \\
\hline 1Z_11 & 40 & 0.5 & 1.0 & $0.5,1.0,1.5$ & 29 d 5 h $50 m$ \\
\hline
\end{tabular}

As the boundary conditions on the inflow we used two values of total discharge $Q\left(20\right.$ and $\left.40 \mathrm{~m}^{3} \cdot \mathrm{s}^{-1}\right)$, three values of bedload transport rate $B\left(0,0.5,1.0 \mathrm{~kg} \cdot \mathrm{m}^{-1} \cdot \mathrm{s}^{-1}\right)$ and suspended load concentration $S\left(0,0.5,1.0 \mathrm{~kg} \cdot \mathrm{m}^{-3}\right)$; models indicated by letter $Z$ and EF_Z are the terrestrial ones and with $T$ and EF_T - Titan's

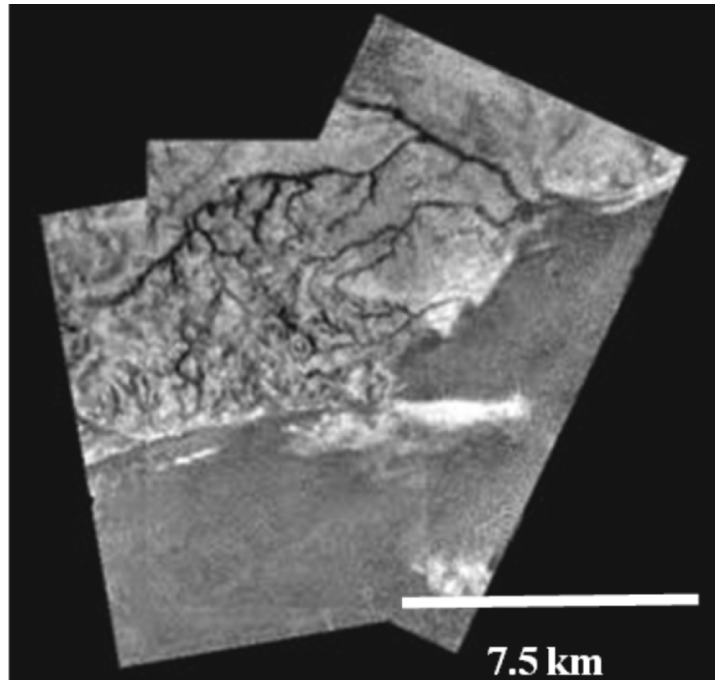

Fig. 4. Photo made by the Huygens probe during descent

We can see the well-developed river valley system; the main type of supply considered for this system is the runoff (Tomasko et al., 2005; Perron et al., 2006, NASA 2005 PIA07236)

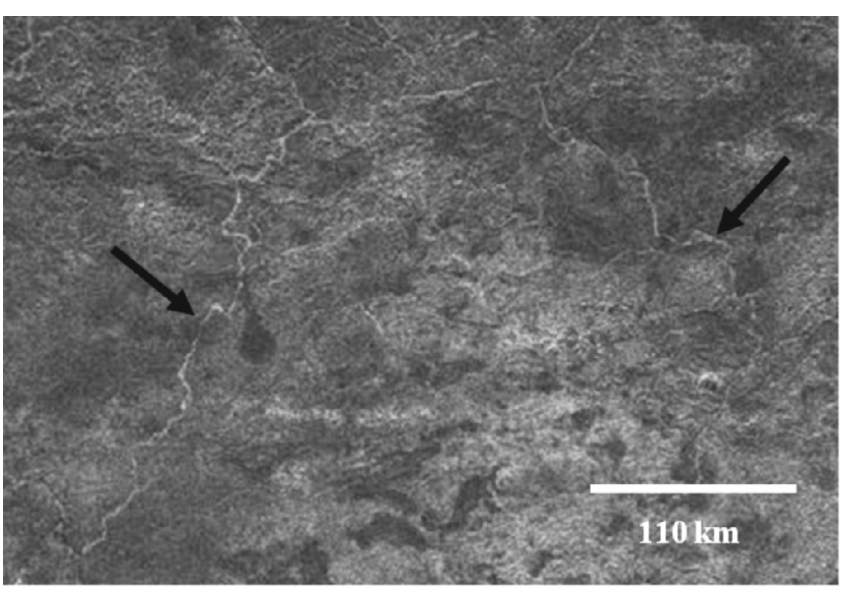

Fig. 5. Meandering dry valleys (indicated by arrows) on Xanadu region (Tomasko et al., 2005; Perron et al., 2006, NASA 2006 PIA08604 - modified) 
Kinematic viscosity and density of the liquids used in our simulations (Cordier et al., 2009; Lorenz et al., 2010; Czechowski and Kossacki, 2012)

\begin{tabular}{|l|c|c|}
\hline \multicolumn{1}{|c|}{ Name } & Kinematic viscosity & Density \\
\hline Symbol & $\mathrm{v}$ & $\rho$ \\
\hline Unit & $\mathrm{m}^{2} \cdot \mathrm{s}^{-1}$ & $\mathrm{~kg} \cdot \mathrm{m}^{-3}$ \\
\hline Water & $1.52 \cdot 10^{-6}$ & 999.84 \\
\hline $\begin{array}{l}75 \% \text { methane } \\
25 \% \text { nitrogen }\end{array}$ & $2.92 \cdot 10^{-7}$ & 518 \\
\hline $100 \%$ methane & $4.58 \cdot 10^{-7}$ & 454 \\
\hline
\end{tabular}

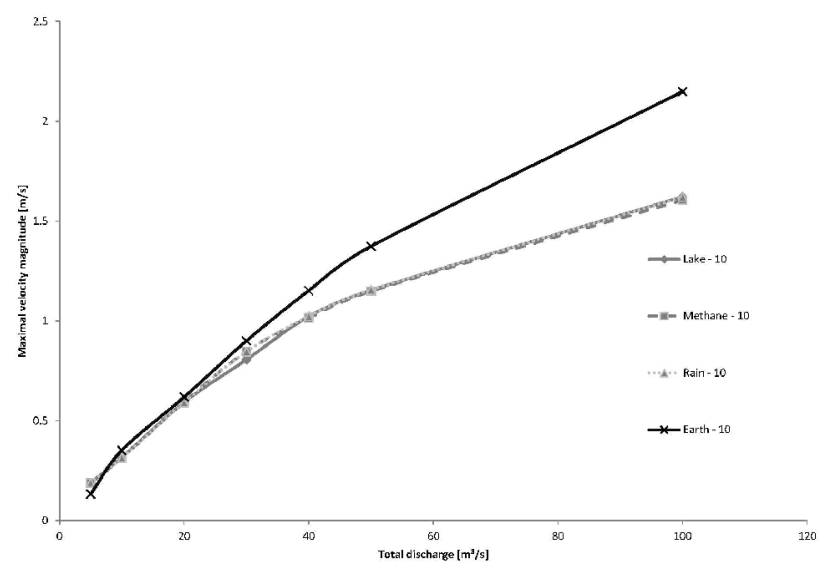

Fig. 6. Maximal velocity magnitude $V_{\max }$ versus total discharge $Q$ for four different liquids

Titan's rain $(75 \%$ methane $+25 \%$ nitrogen), lake liquid $(74 \%$ ethane $+10 \%$ methane $+8.5 \%$ butane $+7 \%$ propane $+0.5 \%$ nitrogen), $100 \%$ methane and water; the lines for three Titan's fluids are overlapping; boundary condition: the level of the liquid on the outflow is assumed to be $10 \mathrm{~m}$ (with respect to the chosen frame of reference); it corresponds to $5.5 \mathrm{~m}$ depth

Table 3
Distributions of grain size of suspended load at the inflow, bedload at the inflow and initial bed composition in the section of the river considered

\begin{tabular}{|l|c|c|c|c|c|c|c|}
\hline Diameter [cm] & 0.01 & 0.1 & 0.25 & 0.5 & 2 & 4 & 16 \\
\hline $\begin{array}{l}\text { Boundary condition for } \\
\text { suspended load at inflow [\%] }\end{array}$ & 35 & 25 & 15 & 15 & 10 & 0 & 0 \\
\hline $\begin{array}{l}\text { Boundary condition for bed } \\
\text { load at inflow [\%] }\end{array}$ & 10 & 10 & 20 & 25 & 25 & 9 & 1 \\
\hline Initial bed composition [\%] & 10 & 10 & 20 & 25 & 25 & 9 & 1 \\
\hline
\end{tabular}

river considered - the fine fraction will become the suspended load, while the coarse fraction will become the bedload.

The specific gravity, i.e. the ratio of (density of grain)/(density of liquid), is an important factor in determining transport and sedimentation (Table 5). We assume that terrestrial grains are composed of pure quartz, and grains on Titan of pure water ice (Table 5; Elachi et al., 2005; Litwin et al., 2012). We know that some organic solids are also present in the regolith of Titan (e.g., Lorenz et al., 2003), but the water ice is the main component (Tomasko et al., 2005). Therefore, in the present calculations we used only water ice for Titan.

\section{NUMERICAL MODEL}

In our research we use a numerical model to determine differences in the evolution of rivers on Earth and on Titan. The dynamical analysis of rivers is performed using the numerical package CCHE2D, adapted for the specific conditions on Titan. The package uses the finite element method. The numerical mesh for the model of East Fork River consists of quadrilateral finite elements with 16533 mesh nodes (for details - see Zhang, 2006). In these mesh nodes the package gives: velocity vector, velocity magnitude (i.e. the absolute value of the velocity), depth of the river, bed change (i.e. the difference of the current bed topography from the initial bed topography), bedload, suspended load, etc. The notation of some parameters used in the paper is shown in Table 6.
Distributions of grain size used by Leopold and Emmett (1976)

\begin{tabular}{|c|c|}
\hline $\begin{array}{c}\text { Grain size } \\
{[\mathrm{mm}]}\end{array}$ & $\begin{array}{c}\text { Grain-size distribution } \\
{[\%]}\end{array}$ \\
\hline $16.0-8.0$ & 1 \\
\hline $8.0-4.0$ & 4 \\
\hline $4.0-2.0$ & 20 \\
\hline $2.0-0.5$ & 45 \\
\hline $0.5-0.25$ & 25 \\
\hline under 0.25 & 5 \\
\hline
\end{tabular}

Table 5

Density of the transported materials and the specific gravity for Earth's and Titan's rivers used in our calculations

\begin{tabular}{|l|c|c|c|c|}
\hline Properties & Symbol & Unit & $\begin{array}{c}\text { Quartz } \\
\text { (concerns Earth) }\end{array}$ & $\begin{array}{c}\text { Water ice } \\
\text { (concerns Titan) }\end{array}$ \\
\hline Density & $\rho$ & $\mathrm{kg} \cdot \mathrm{m}^{-3}$ & 2650.0 & 980.0 \\
\hline \multicolumn{3}{|l|}{} & specific gravity \\
\hline Substances & 2.650 \\
\hline Quartz/water & 1.892 \\
\hline Water ice/liquid of composition of Titan's rain &
\end{tabular}


Table 6

Notation of some parameters used in the paper

\begin{tabular}{|l|l|}
\hline Symbol & \multicolumn{1}{|c|}{ Meaning of symbol } \\
\hline$Q$ & total specific discharge $\left[\mathrm{m}^{3} \cdot \mathrm{s}^{-1}\right]$ \\
\hline$V$ & velocity magnitude depth-averaged $\left[\mathrm{m} \cdot \mathrm{s}^{-1}\right]$ \\
\hline$\delta_{z b}$ & maximal bed change for given time $[\mathrm{m}]$ \\
\hline$D 50$ & median of particle size distribution $[\mathrm{m}]$ \\
\hline$D 50_{\max }$ & maximal median of particle size distribution $[\mathrm{m}]$ \\
\hline$S$ & suspended load concentration $\left[\mathrm{kg} \cdot \mathrm{m}^{-3}\right]$ \\
\hline$S_{\max }$ & maximal suspended load concentration $\left[\mathrm{kg} \cdot \mathrm{m}^{-3}\right]$ \\
\hline$B$ & bedload transport rate $\left[\mathrm{kg} \cdot \mathrm{m}^{-1} \cdot \mathrm{s}^{-1}\right]$ \\
\hline
\end{tabular}

Subscript "max" denotes the maximum value of the given parameters for the part of the river considered
Titan's rain. It is also the liquid most likely to be found in Titan's rivers (Perron et al., 2006; Atreya et al., 2009; Strobel et al., 2009).

A few other results of the short simulations are presented in Table 7. General properties of the flows in Titan's and terrestrial rivers are also compared in this table.

The next parameter of the flow investigated in the short simulations is the velocity magnitude $V$. The dependence of the maximum value of $V-V_{\max }(Q)$ - could be represented by a piecewise linear function of total discharge $Q$ (Fig. 6). Note that for a lower total discharge (i.e. for $Q<40 \mathrm{~m}^{3} \cdot \mathrm{s}^{-1}$ ) the slope of the graphs is steeper than for a higher $Q$, i.e. the rate of change for $V_{\max }$ decreases with $Q$.

In the short simulations we also solved the problem of the transient effects of the flow. For some time after starting the simulation, there are temporary effects resulting from certain specific initial conditions. These transient effects do not exist in natural rivers (they do not have a starting time). The results are presented in Figure 7 . The figure presents the $x$-component of the velocity vector $U$ in a few chosen mesh nodes.
ADDITIONAL PARAMETERS OF THE MODEL

We used the following gravitational acceleration: $g_{e}=$ $9.817 \mathrm{~m} \cdot \mathrm{s}^{-2}$ (for Earth), $g_{t}=1.352 \mathrm{~m} \cdot \mathrm{s}^{-2}$ (for Titan). Since many details about Titan's rivers are still unknown, we chose the same values of the required parameters as for terrestrial meandering rivers. The von Karman constant is assumed to be 0.41 (see also discussion in Frenzen and Vogel, 1994). The grain-size distribution could be characterized by the parameter known as median of particle size distribution, $D 50$. Its definition assumes that the total mass of grains smaller than $D 50$ is equal to half of the total mass. For our distribution $D 50=0.5 \mathrm{~cm}$ (calculated on the basis of Table 4). The porosity of bed sediments is assumed to be $24 \%$. In our simulations the material is transported only as the bed load and as the suspended load. For the values of $Q$ used in our simulation, the flow is approximately steady and the bed change is relatively slow. Note that the domain of calculations is constant, so lateral boundaries represent "rigid banks" that cannot be eroded. Fortunately, the stream of the river modelled is narrower than the domain, so the stream is often separated from the boundary of the domain by belts of the bed material. These belts could be a subject of erosion, so the minor lateral motion of the river channel could be also simulated (in the range of the domain).

\section{RESULTS}

\section{THE RESULTS OF SHORT SIMULATIONS}

A series of short simulations was performed to solve some specific problems. The transport of sediments is not included in this series. First, we had to know whether simulations with many liquids on Titan are necessary. Therefore, the flows with different liquids are simulated for $\sim 60 \mathrm{~min}$. We found that all the liquids considered (Table 2) gave similar flow properties (e.g., see $V_{\max }$ in Fig. 6). Based on this result, for the rest of the simulations we used only one fluid; the one that corresponds to

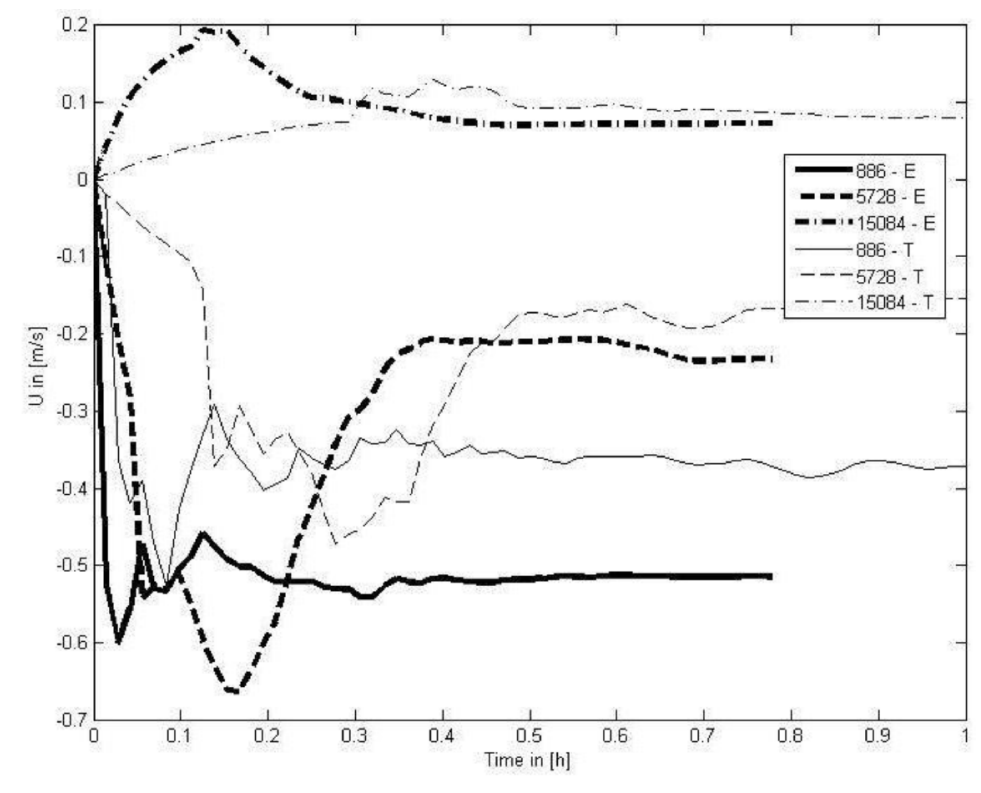

Fig. 7. The dependence of $\mathrm{x}$-component of the velocity vector $U$ versus time in three chosen mesh nodes, for Titan (T) and for the Earth (E) (see Fig. 3 for positions of the mesh nodes)

Note that stabilization of the flow is reached after $\sim 0.5 \mathrm{~h}$ 
The mesh nodes are chosen in the following way (see Fig. 3 for positions of the mesh nodes): in the upper course (no. 886), in the mid course (no. 5728), and in the lower course (no. 15084). For all these three mesh nodes, we assumed the same $Q=40$ $\mathrm{m}^{3} \cdot \mathrm{s}^{-1}$. Figure 7 shows that stabilization is reached after $\sim 0.5 \mathrm{~h}$.

\section{RESULTS OF SIMULATIONS OF SEDIMENT TRANSPORT}

The calculations of flow are used for simulations of erosion and sedimentation (Misiura and Czechowski, 2013). Consider now the changes of the topography of the river channel resulting from those processes. The changes are expressed by bed changes with respect to the initial bed topography. Generally, for low values of total discharge $Q$, the bed changes are low (i.e., the changes of topography are rather limited). For large values of $Q$, the bed changes are large.

Figure 8 presents maximal bed change $\left(\delta_{\mathrm{zb}}\right)$ as a function of total discharge $Q$. For discharge lower than $15 \mathrm{~m}^{3} \cdot \mathrm{s}^{-1}$, the bed change for Titan is slightly higher than for Earth. The situation changes for higher $Q$; the bed change for Earth is significantly

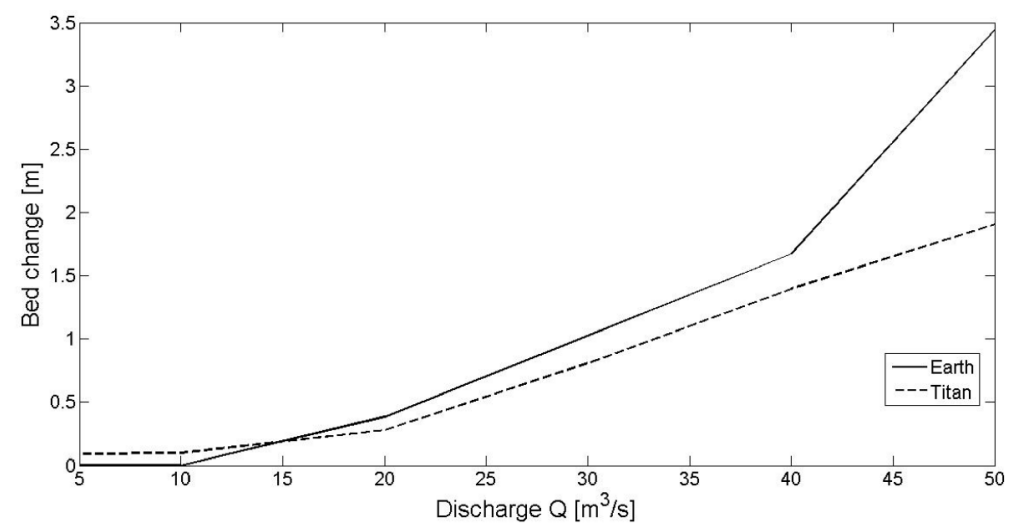

Fig. 8. Maximal bed change $\delta_{z b}$ versus discharge $Q\left[m^{3} \cdot \mathbf{s}^{-1}\right]$

Boundary condition: the level of the liquid on the outflow is $8 \mathrm{~m}$; that corresponds to $\sim 4 \mathrm{~m}$ depth; note that for $Q>25 \mathrm{~m}^{3} \cdot \mathrm{s}^{-1}, \delta_{\mathrm{zb}}$ is higher for the Earth than for Titan

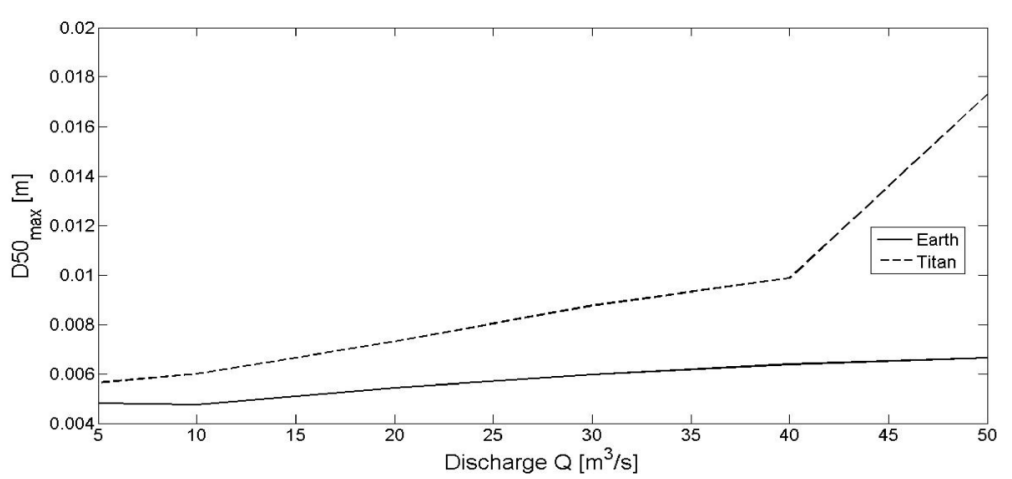

Fig. 9. Maximal values of median of particle size distribution $D 50_{\max }$ versus discharge $Q\left[\mathrm{~m}^{3} \cdot \mathrm{s}^{-1}\right]$

Boundary condition: the level of the liquid on the outflow is $7 \mathrm{~m}$; that corresponds to $\sim 3 \mathrm{~m}$ depth; note that $D 50_{\max }$ characterizes the whole part of the river channel considered higher than for Titan. However, the later evolution for very long simulations (e.g., 50 days) is different (see Fig. 16).

The distribution of sediments in the river bed could be characterized by $D 50$. If $D 50$ is low, then the channel bed is built by grains of small diameters. For high $D 50$, large grains dominate. The changes of $D 50$ in time are large and they strongly depend on $Q$. Figure 9 presents $D 50_{\max }$, i.e. the maximum value of $D 50$. One can see that $D 50_{\max }$ is an increasing function of $Q-$ as would be expected. Moreover, for Titan's conditions, $D 50_{\max }(Q)$ is larger than the $D 50_{\max }(Q)$ for Earth for the considered range of $Q$. Also, the rate of increase is larger on Titan than on Earth. Both of these statements are in agreement with existing publications (e.g., Burr et al., 2006). It means that in some parts of the channels on Titan the coarse sediments accumulate more effectively than on Earth, and the finer sediments are also removed more effectively (see also Fig. 13). This fact could be explained by considering buoyancy and hydrodynamic forces (e.g., Burr et al., 2006).

Consider now changes of $D 50_{\max }$ in time for constant $Q=$ $30 \mathrm{~m}^{3} \cdot \mathrm{s}^{-1}$ (Fig. 10). Initially, for time below $\sim 2.5 \cdot 10^{4} \mathrm{~s}=\sim 7 \mathrm{~h}$, $D 50_{\max }$ for Titan is higher than for Earth. This means that on Titan, small grains are being more easily removed out of the part of the river channel considered. For longer periods (for time $>4 \cdot 10^{4} \mathrm{~s}=\sim 11 \mathrm{~h}$ ), $D 50_{\max }$ is larger for Earth. This figure suggests that, initially, fine material is eroded faster on Titan than on Earth. This conclusion is not a result of assumed grain-size distribution, because we assumed the same distributions for Titan and Earth. Therefore, the difference in behaviour is the result of different conditions on these celestial bodies.

\section{CASE STUDY ON BEHAVIOUR OF THE RIVER MODELS}

Below we discuss some examples of the processes considered in the river models. Figures 11 and 12 present sedimentation and erosion in the river channel for Titan (Fig. 11) and for Earth (Fig. $12)$ for the same initial and boundary conditions $(Q$ $=40 \mathrm{~m}^{3} \cdot \mathrm{s}^{-1}$, transport rate of bedload $B=1 \mathrm{~kg} \mathrm{~m}^{-1}$. $\mathrm{s}^{-1}$ and concentration of suspended load $S=0.5$ $\mathrm{kg} \cdot \mathrm{m}^{-3}$ - models 1T_6 and 1Z_6 in Table 1).

For Titan (Fig. 11), we can see the formation of the characteristic structure of the meandering river: on the inside bend of meanders there are accumulation structures - point bars, while on the other side, the bank is eroded, and so the material is accumulated and eroded in expected locations. For a much longer simulation than we made in this work, the effect of lateral migration of the channel would be visible. This effect is characteristic for meandering rivers.

For Earth (Fig. 12), point bars and mid-channel bars formed. This type of channel could evolve into a braided river with a longer simulation than we made in this work.

Figure 13 presents the distribution of the final bed composition for the model 1T. For Titan's condition, the following sequence of distributions of fractions in river channel is observed: the coarsest sediments are in the mainstream, while moving away from the mainstream the contribution of finer sediments is increasing. 


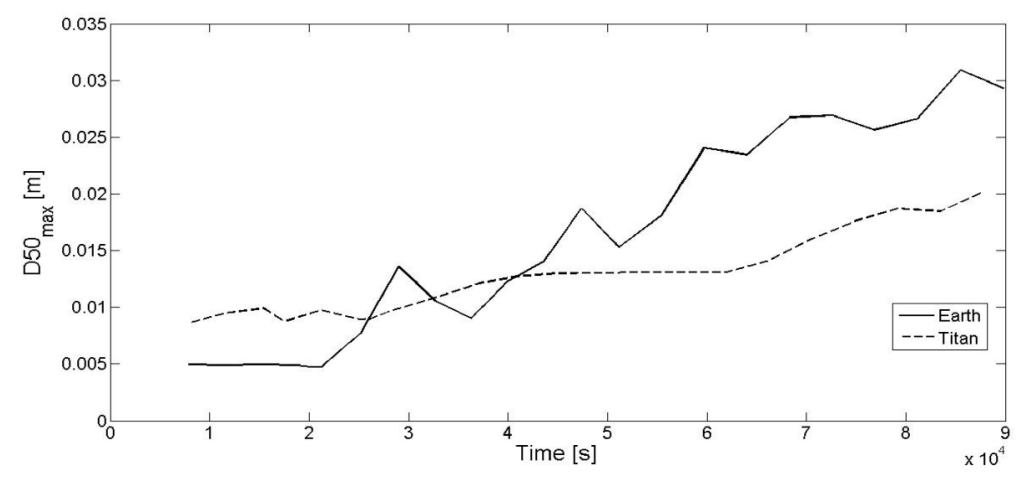

Fig. 10. Maximal values of the median of particle size distribution $D 50_{\max }$ versus time

Note that for duration shorter than $\sim 2.5 \cdot 10^{4} \mathrm{~s}(\sim 7 \mathrm{~h}), D 50_{\max }$ for Titan is higher than $D 50_{\max }$ for Earth, and for duration longer than $\sim 4 \cdot 10^{4} \mathrm{~s}(\sim 11 \mathrm{~h})$ the situation changes $-D 50_{\max }$ for Earth is higher than $D 50_{\max }$ for Titan; the fluctuation in the graph for the Earth is the result of the general sensitivity of maximal values to the details of the model; boundary condition: the level of the liquid on the outflow is $10 \mathrm{~m}$; this corresponds to $\sim 6 \mathrm{~m}$ depth

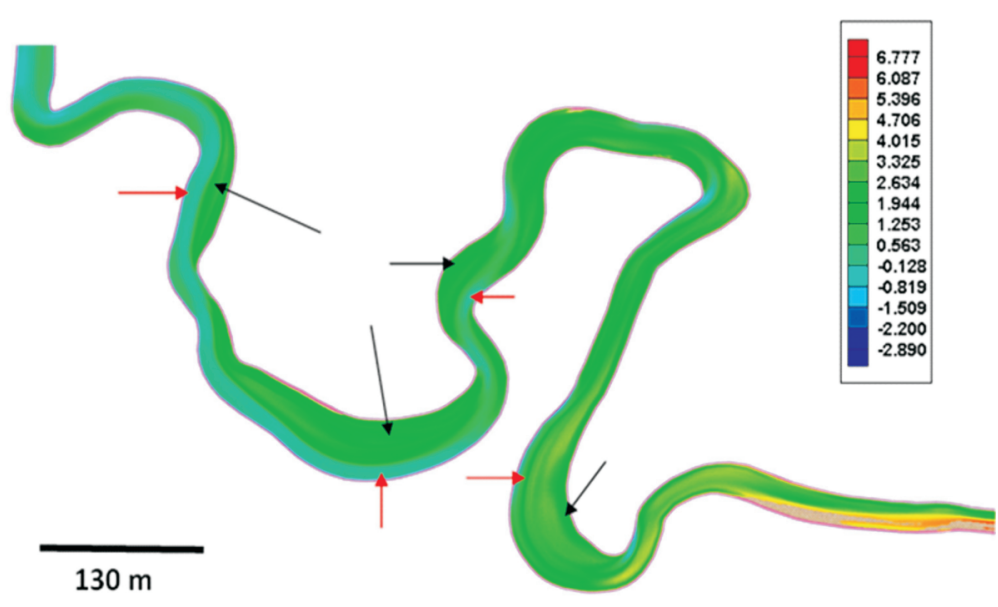

Fig. 11. The bed change after $\sim 46$ days, simulation for Titan (model 1T_6)

Black arrows indicate point-bars (results of accumulation); red arrows indicate structures of erosion
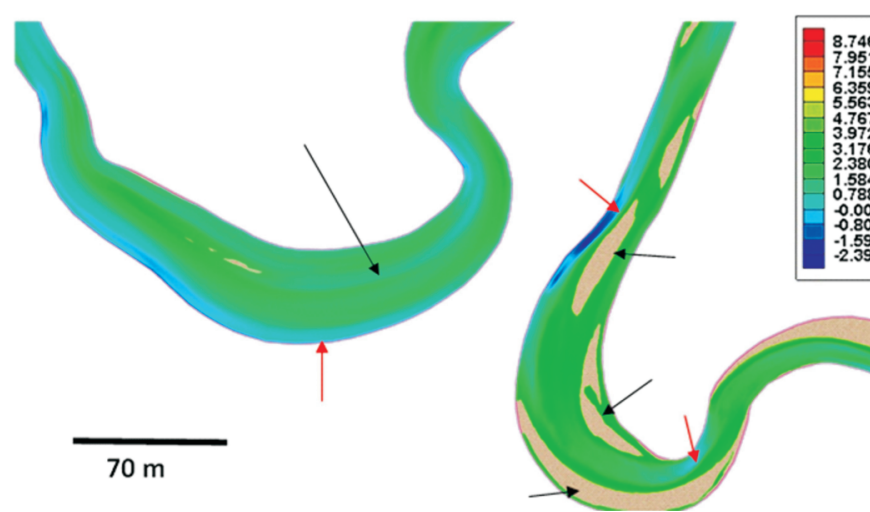

$70 \mathrm{~m}$

Fig. 12. Simulation for the Earth (model 1Z 6), the bed change after $\sim 11$ days

For explanations see Figure 11
The results discussed in this subsection indicate that the package CCHE2D gives realistic results for Titan's as well as for terrestrial conditions. Note also that the package is often used in practical applications and scientific research (e.g., Magnuszewski and Gutry-Korycka, 2009a, b), therefore its use for our modelling is fully justified.

\section{RESULTS OF SIMULATIONS}

The strategy of this work is to investigate differences in the processes in Titan's rivers compared to terrestrial ones, instead of making a model of a specific river on Titan. In fact, the present data concerning any of Titan's rivers are not sufficient for such modelling (e.g., the lack of bed topography). Our method of investigation requires also the use of the same values of corresponding parameters of rivers on Titan and Earth unless the basic differences of liquids (hydrocarbon versus water), solids (water ice versus silicate grains), and conditions (e.g., different gravity) require the opposite. For this reason we use the same geometry and distribution of grain size for Titan's and for terrestrial rivers.

In the long simulations we modelled the rivers' evolutions for 22-66 days (Table 1). Generally, these calculations confirm the results presented in subsection "The results of short simulations". Moreover, we found some new properties that we discuss below.

In this subsection, we investigate how the transport and accumulation of the material depend on some boundary conditions. In our simulation we use various boundary conditions, for example: transport rate of bedload, concentration of suspended load, and total discharge (see Table 1).

Based on the result of the short simulation we decided to use two values of total discharge $Q=20$ $\mathrm{m}^{3} \cdot \mathrm{s}^{-1}$ and $40 \mathrm{~m}^{3} \cdot \mathrm{s}^{-1}$ for which the topographic bed change rises rapidly with increasing $Q$ (Fig. 8). However, the initial long simulations indicated that $Q=20 \mathrm{~m}^{3} \cdot \mathrm{s}^{-1}$ is too low, because after $\sim 20$ days some of the simulated rivers dry locally (e.g., 1T_2); this makes further calculations impossible. For discharge $40 \mathrm{~m}^{3} \cdot \mathrm{s}^{-1}$ this effect does not appear. Our model does not include evaporation or infiltration (see parameters of the model in Section Material Properties). The "drying" means that discontinuity of the water stream is observed. Generally, this is a physical effect observed if sandy bedforms slow down the flow in the upper course of the river, while in the lower course the flow is not slowed down. Then the stream in the midcourse becomes so narrow that it is below the resolution of the numerical model.

For some values of the transport rate of the bedload and the concentration of the suspended load we found interesting differences between $\mathrm{Ti}$ tan's and Earth's rivers. For Earth (for $Q=40 \mathrm{~m}^{3}$. $\mathrm{s}^{-1}$, transport rate of bedload $B=1 \mathrm{~kg} \cdot \mathrm{m}^{-1} \cdot \mathrm{s}^{-1}$ and concentration of suspended load $S=0.5 \mathrm{~kg} \cdot \mathrm{m}^{-3}$ ), a river evolves towards a quasi-braided river (Fig. 12). For the same boundary conditions the river on 

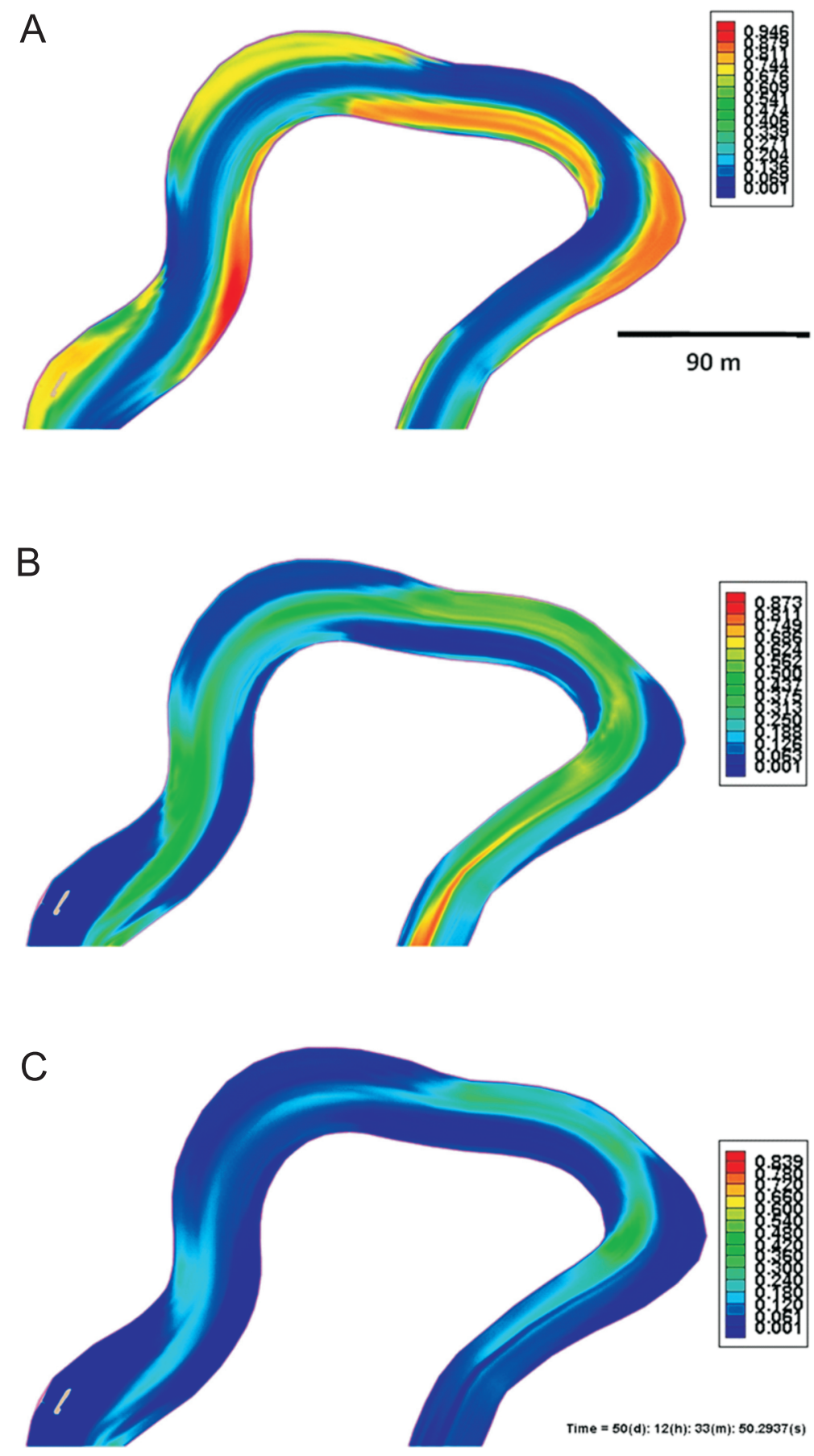

Fig. 13. Final bed composition for simulation 1T (Titan) for the chosen meander

The scale is from blue $(0 \%)$ to red $(100 \%)$ showing the given particle size in all sediments; A - sand $-0.01 \mathrm{~cm}$; B - gravel $-2 \mathrm{~cm}$; C - pebble $-4 \mathrm{~cm}$; note that the largest grains accumulate in the main stream, while the finest sediments accumulate mostly in the point-bars

Titan is still a regular meandering river (Fig. 11). We believe that this could be an important result of our models. The evolution toward a quasi-braided river is a result of a large volume of sediments that could not be transported further in terrestrial conditions, and are deposited in the modelled section of the river. We hoped that we could determine the conditions necessary for de- veloping typical braided rivers on Titan. Note, that the number of channels of a given river could be determined even from data with the present resolution, so some limits on the properties of liquids or solids in Titan's rivers could be determined.

Let us discuss now the rate of sedimentation. Figure 14 presents evolution of the bed along a chosen cross-section (thick line in Fig. 3). One can conclude that the rate of sedimentation on Titan is higher than on Earth. The layers of new sediments on Titan have thicknesses of 10-40 cm. For terrestrial conditions, the rate of sedimentation is much lower and subsequent layers are thinner $(\sim 5 \mathrm{~cm})$. Similar behaviour is observed along other crosssections. This situation could have two causes:

- flow in Titan's rivers has a higher effective power compared to the power required for moving bedload;

- the power of terrestrial rivers are too high, so material cannot accumulate. Burr et al. (2006) and Witek and Czechowski (2013, 2014) suggest that the first option is correct.

This means that the effective power of a stream on Earth is lower than on Titan, so the effect of this stream on suspended load is also lower. Such a situation could be the result of lower gravity on Titan or a lower viscosity of fluid in Titan's rivers.

The result discussed in the previous paragraph is confirmed by our other simulations. For Titan the coarse sediments accumulate in the lower course of the river (see distribution of $D 50$ in river channel in Fig. 15).

The bed change for the chosen mesh nodes is given in Figure 16 (see Fig. 2 for positions of the mesh nodes). Initially, the rate of the bed change for the Earth is very large, but after $300 \mathrm{~h}$ the rate drops almost to zero and the bed change is constant. For Titan, the rate of the bed change is almost constant from 100 to $1100 \mathrm{~h}$, however, it is smaller than that on the Earth. The average bed change (averaged over whole numerical domain) for Titan is higher than for Earth. This is a result of the larger rate of transport of material on Titan. Note that the same mass of the bed load and suspended load (for Titan and Earth) is assumed for this simulation. Analogous simulations performed for the same volume of transported material gave similar results, i.e. the bed change for Titan in this mesh node is larger than that for Earth.

Below, values of some quantities in a chosen mesh node are considered. We chose a typical mesh node, thus similar conclusions could be made on the basis of other mesh nodes. The magnitude of velocity of fluid in rivers is shown in Figure 17. The velocity is significantly lower on Titan than in the terrestrial river $\left(1 \mathrm{~m} \cdot \mathrm{s}^{-1}\right.$ versus $\left.1.5 \mathrm{~m} \cdot \mathrm{s}^{-1}\right)$. This suggests that the main sources of difference in transport and sedimentation are gravity, densities of fluid and sediments, and different buoyancy force, rather than the velocity.

Generally, a larger velocity means a higher effective power of river. Our simulations show that some exceptions are possible. The transport on Titan is more effective even for significantly lower velocities. Similar behaviour is observed also in other points (mesh nodes). 
A

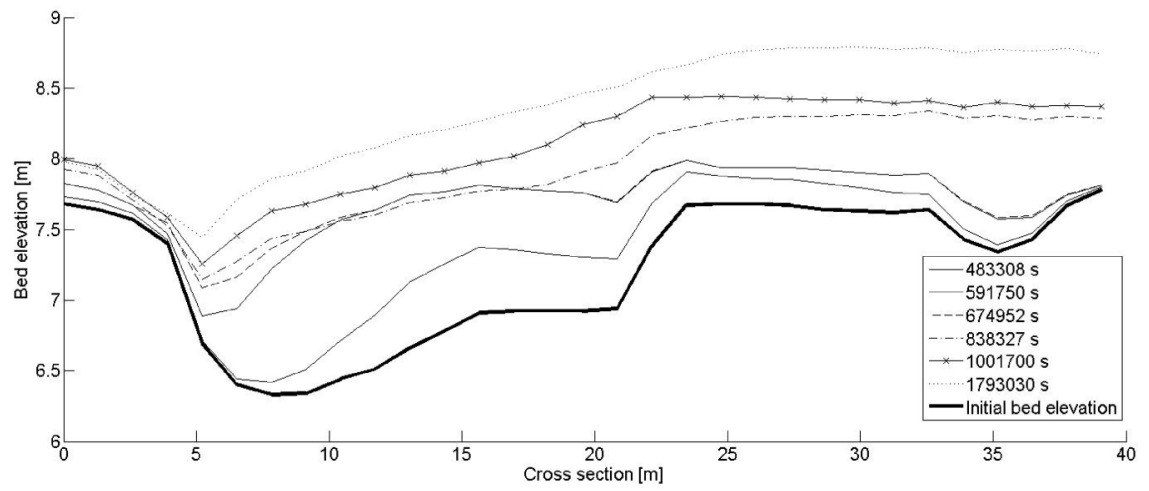

B

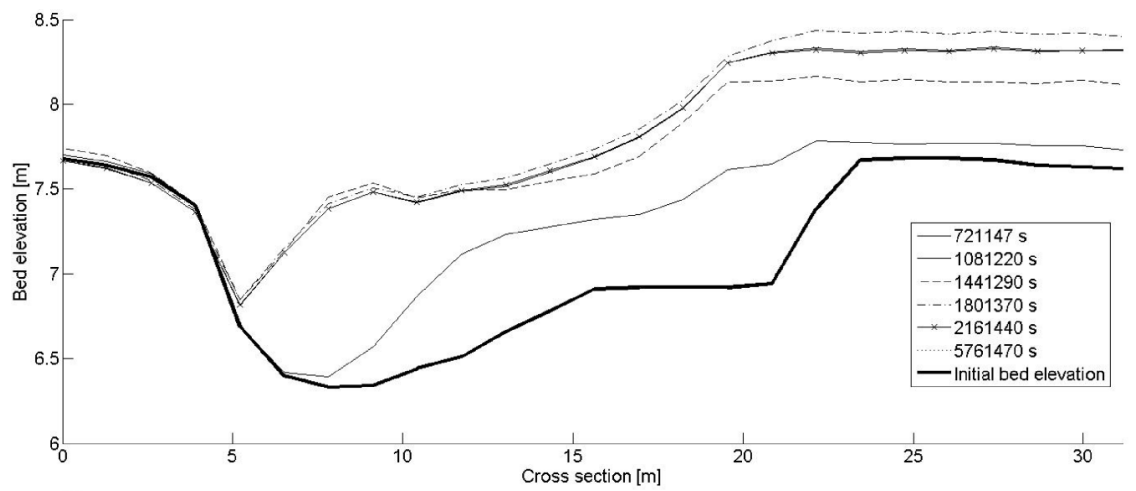

C

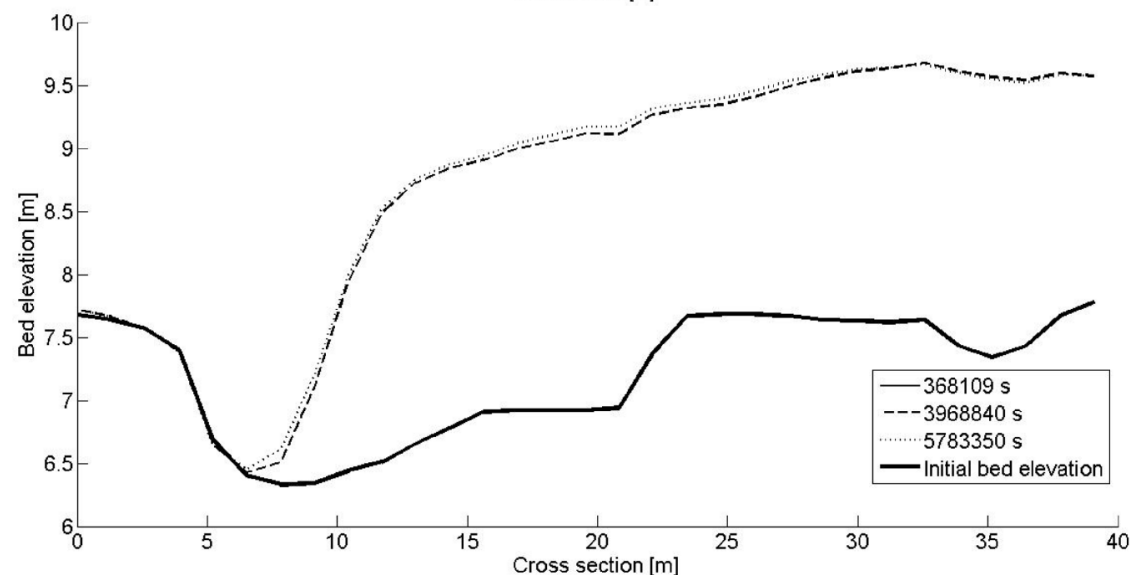

D

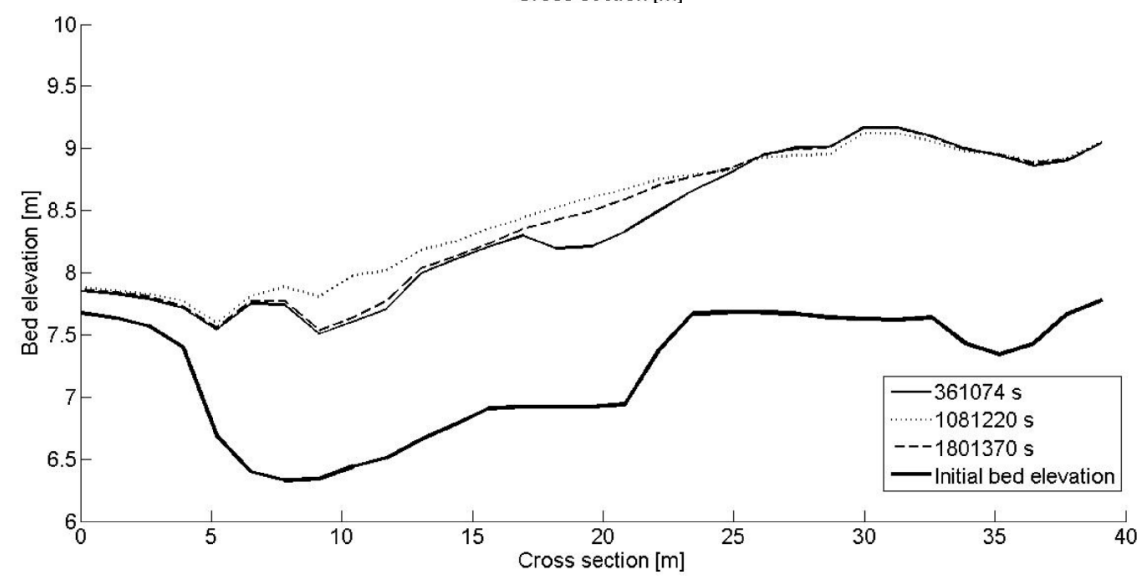

Fig. 14. Evolution of river's topography

The cross sections across the river along chosen line $(J=172)$ and for different times (see legends); $\mathbf{A}$ - for simulations 1T_2 (Titan); $\mathbf{B}-$ for simulation 1Z_2 (Earth). Maximal duration of simulation is $\sim 21$ days (i.e. $1793030 \mathrm{~s}$ ) for Titan (A) and $\sim 24$ days (i.e. $2 \overline{121} 930 \mathrm{~s}$ ) for the Earth (B). The lower black, thick, dashed line indicates the initial bed elevation of the river bed. The vertical black line indicates position of the mesh node 5620 and the vertical black dashed line indicates the mesh node 5633. The total thickness of sediment on Titan is larger than on the Earth (note different vertical scales of the both panels), e.g. for the distance equal $15 \mathrm{~m}$ the thickness of sediments on Titan is $\sim 1 \mathrm{~m}$ while at the same mesh node on the Earth the thickness is $\sim 0.5 \mathrm{~m}$. C and $\mathbf{D}$ shows models $1 T$ _6 (Titan) and 1Z_6 (Earth), respectively 

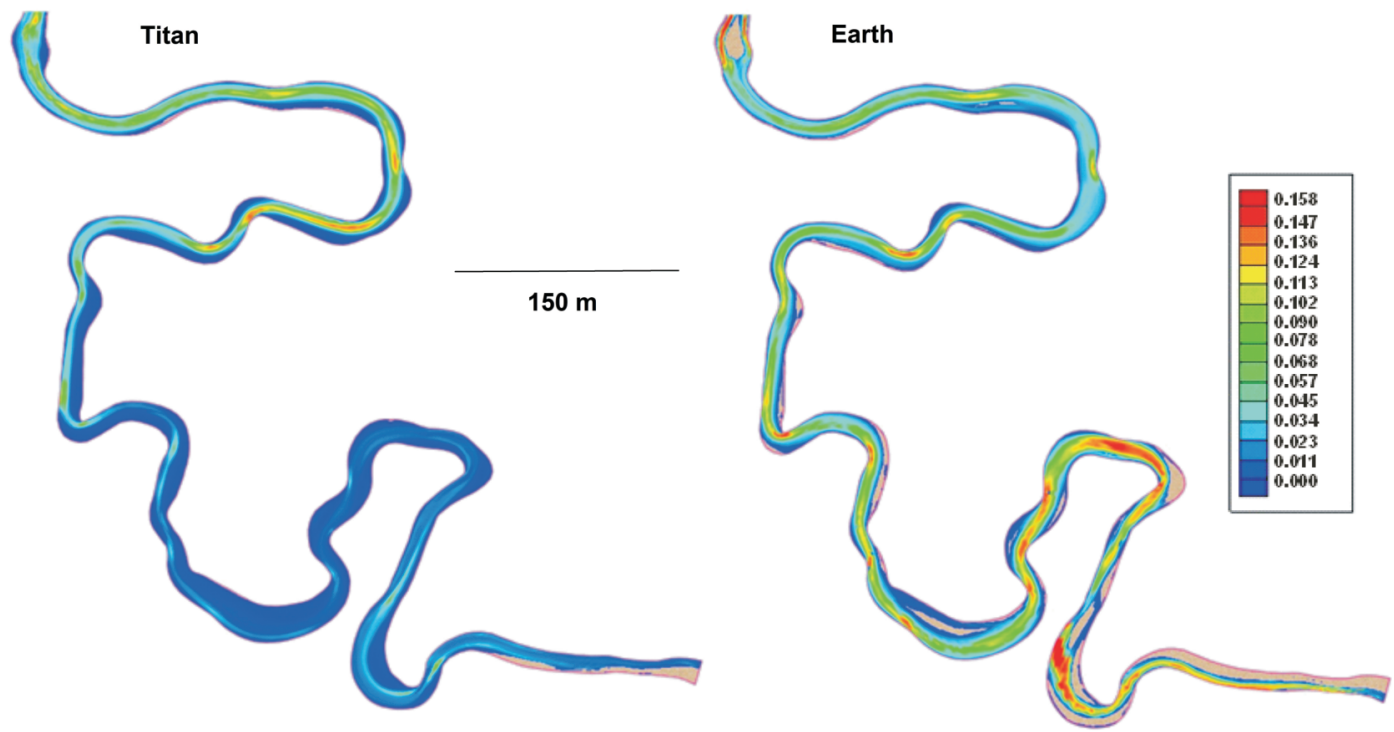

Fig. 15. Distribution of D50 for Titan and the Earth after $\sim 66$ days for simulations 1Z_6 and 1T_6

Note that $D 50$ in the upper course on Titan is very low (i.e. the bed consists of small grains) and $D 50$ increases downstream; on the Earth the situation is different - there is not such a large difference between the upper and the lower courses; distribution of D50 on the Earth is relatively stable; to obtain similar stability of D50 on Titan, longer simulations are necessary

A

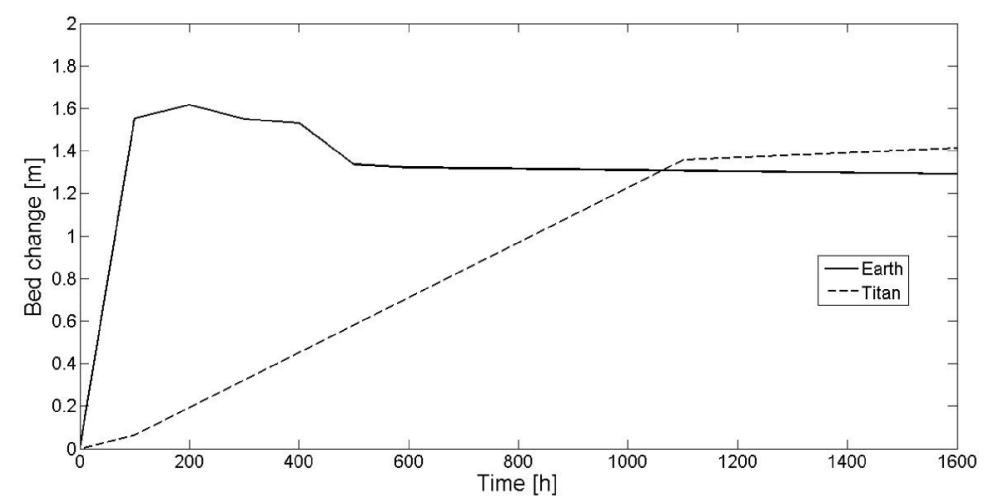

B

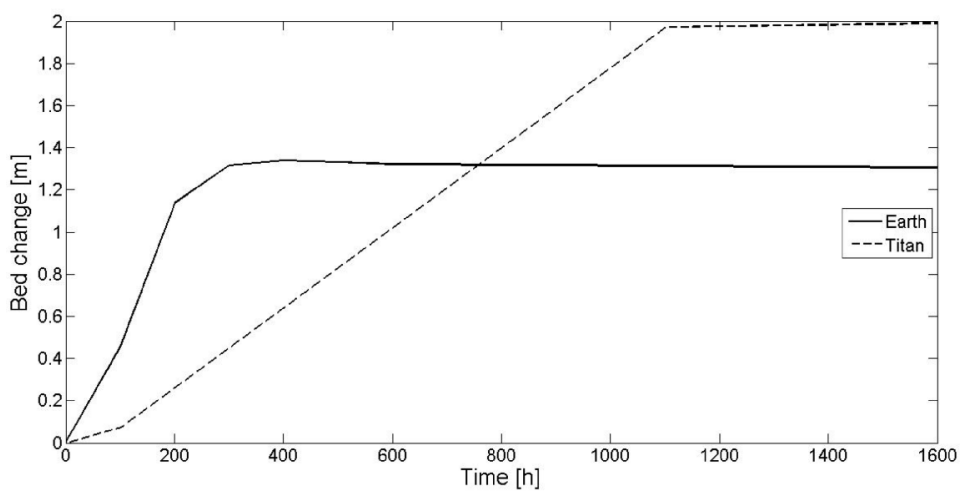

Figure 18 presents comparisons of the suspended load and the bedload for Titan and Earth for mesh node 5620. Simulations show that for Titan the maximal value of suspended load concentration is around $23 \mathrm{~kg} \cdot \mathrm{m}^{-3}$, while on Earth it is only around $3 \mathrm{~kg} \cdot \mathrm{m}^{-3}$. On the other hand, bedload transport rate is much greater on Earth than on Titan - the maximal value is around $0.3 \mathrm{~kg} \mathrm{~m}^{-1} \cdot \mathrm{s}^{-1}$ on Earth and negligible on Titan. This fact suggests that the dominant mode of transport on Titan is the suspended load.

A direct comparison of the transport of solid material as suspended load and as bedload requires

Fig. 16. The bed change for the chosen mesh nodes versus time for simulations $12 \_6$ and 1T_6

A - mesh node 5620 is close to the main stream of the river, B - mesh node 5633 is in the point-bar; for mesh nodes location see Figure 3. Note that initially the rate of bed change for the Earth is very high. After $\sim 300 \mathrm{~h}$ (at B) or $\sim 100 \mathrm{~h}$ (at $\mathrm{A}$ ) the rate drops to $\sim 0$ and the bed level is constant or even some erosion is observed. This means that topography after $\sim 1200 \mathrm{~h}$ is relatively stable; but the deposition in the point-bars for Titan is significantly higher than for the Earth, while deposition in the riverbed (close to the main stream) is similar. For Titan the rate of bed change is constant from 100 to $1100 \mathrm{~h}$ (for both mesh nodes) and it is lower than on the Earth. However, the final total bed change for Titan is eventually higher $(\sim 2 \mathrm{~m}$ at $\mathrm{B}$ and $\sim 1.4 \mathrm{~m}$ at $\mathrm{A})$. This is a result of larger volume of transported material on Titan (the same mass of the material is assumed) 


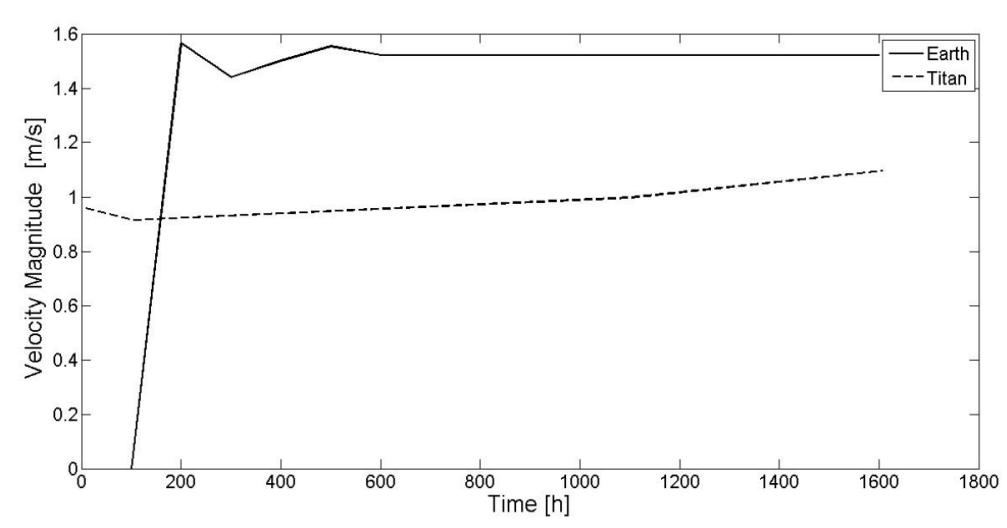

Fig. 17. Changes of the velocity magnitude $V$ versus time in the mesh node 5620

Results for simulations 1T_6 (solid line) and 1Z_6 (dashed line) are presented some further consideration because $S$ and $B$ have different units and different physical meanings; $S$ is the mass of suspended load in $\mathrm{kg}$ per $1 \mathrm{~m}^{3}$, while $B$ is the mass of bedload in $\mathrm{kg} \cdot \mathrm{s}$ transported through $1 \mathrm{~m}$ (perpendicular to the velocity vector) of the bed in 1 second (see also Table 6). For this reason we introduce a modified suspended load defined as: $S_{\text {mod }}=S \cdot V \cdot d$, where $d$ is the local depth of the river. After this operation $S_{\text {mod }}$ has the same unit as $B$, so they could be directly compared. Figure 19 presents the ratio of $S_{\bmod }$ and $B$ versus time for a chosen mesh node. For Titan, the ratio is always very high (sometimes even $S_{\bmod }>\sim 31,000 B$ ). For Earth, the ratio is significantly lower than for Titan (from $\sim 0.1$ to 297). The ratio changes through time as a result of evolution of the river bed. Both models start from the same initial topography, so direct comparison could be made for time $t<\sim 1000000 \mathrm{~s}=11 \mathrm{~d}$ (see also Fig. 12). Further evolution of the terrestrial river leads to a quasi-braided river, while for Titan we still
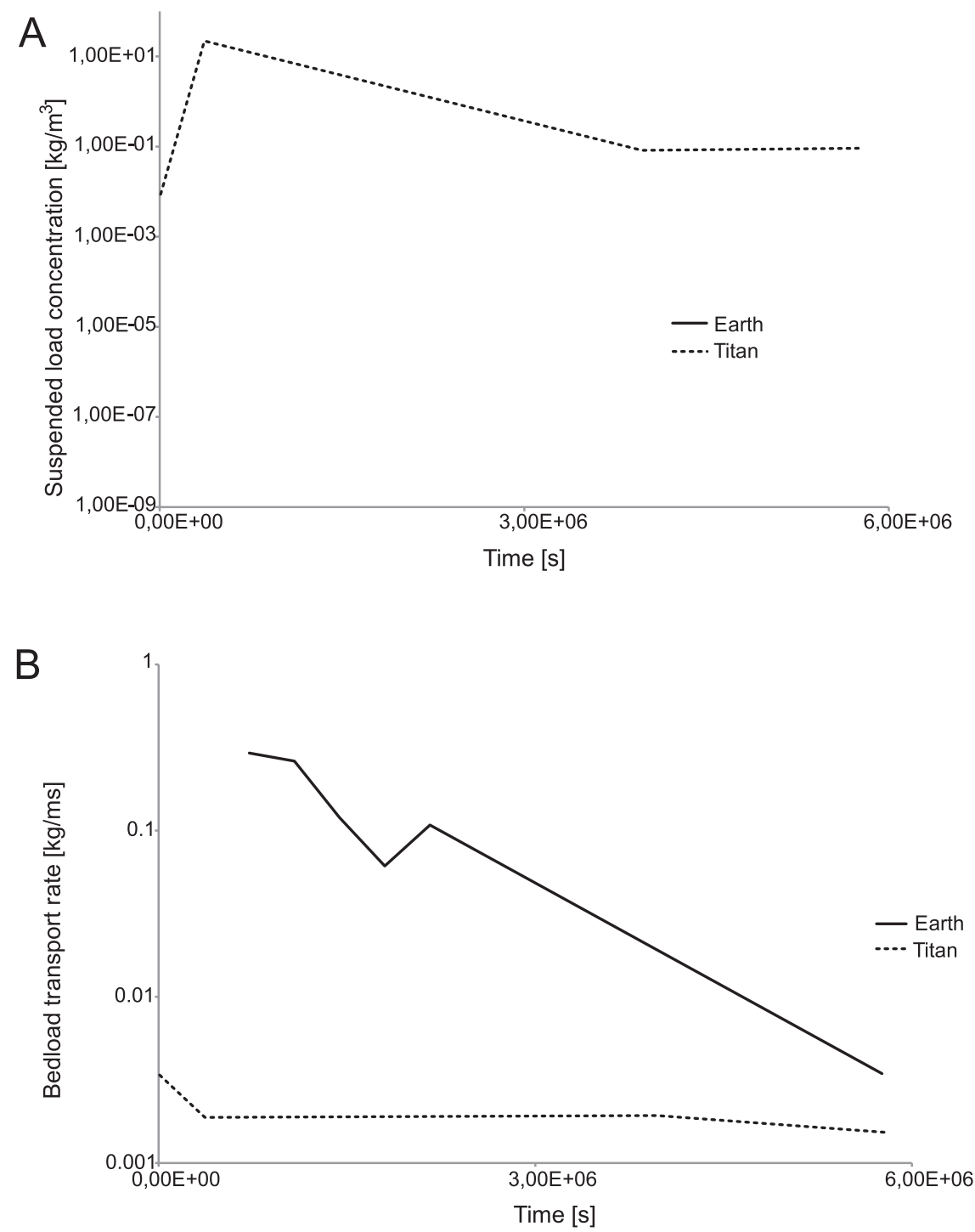

Fig. 18A - suspended load concentration; B - bedload transport rate versus time for mesh node number 5620 for simulations $1 T \_6$ and $1 Z_{-} 6$ 


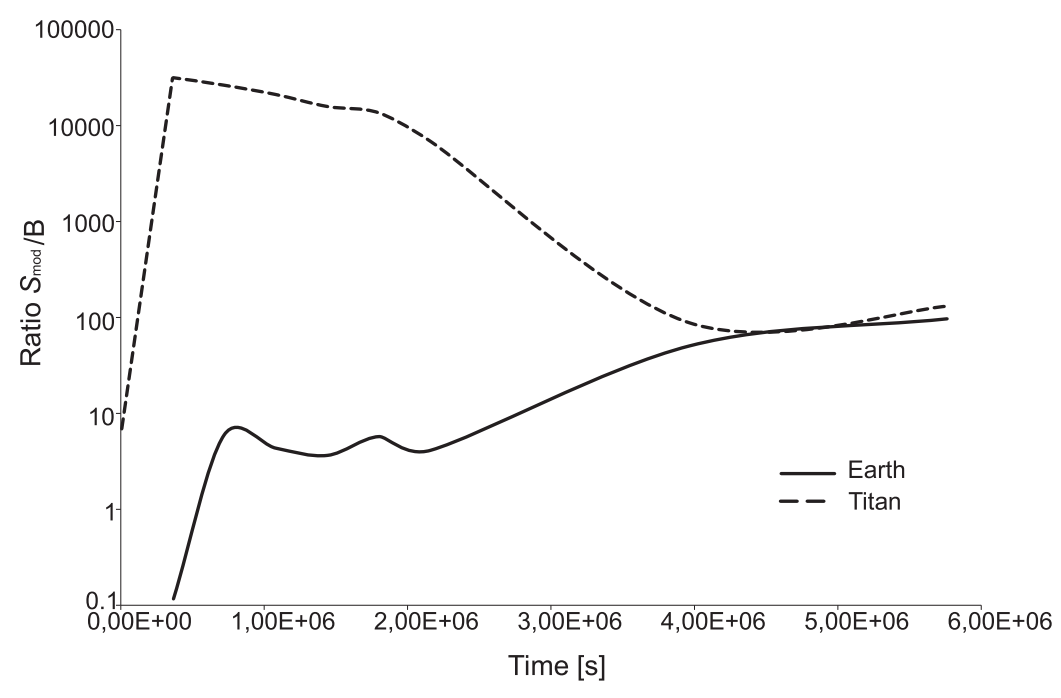

Fig. 19. Ratio of modified suspended load concentration $S_{\bmod }$ to bedload transport rate $B$ versus time for mesh node number 5620 for simulations 1T_6 and 1Z_6

have a typical meandering river for the entire duration of the simulation. Note that the chosen mesh node 5620 could be treated as a typical one. Figure 19 confirms that for Titan's rivers the suspended load is the main method of transport. For the Earth, the behaviour of the considered ratio is more complicated. The suspended load Smod could be of the same importance as the bedload, lower, or significantly higher, but not higher than $\sim 100 \mathrm{~B}$.

This conclusion is confirmed also by comparison of the whole mass of the sediments transported as suspended load $S_{\text {mod }}$ during modeled time $t^{\text {sim }}$ through the mesh node 5620 . The mass is given by the following time integral: $K=\int{ }^{t s i m} 0$ $S_{\text {mod }} \mathrm{dt}$ in the chosen mesh node. The calculation gives 2.8 . $10^{6}\left[\mathrm{~kg} \cdot \mathrm{m}^{-1}\right]$ for the Earth and $1.18 \cdot 10^{8}\left[\mathrm{~kg} \cdot \mathrm{m}^{-1}\right]$ for Titan.

For Titan, the total mass of transported material through this mesh node as suspended load is 42 times higher than for Earth. Integration across the river width leads to a similar conclusion transport by suspended load is more effective for Titan than for Earth. The total transport of the river (suspended load + bedload) is also higher for Titan. These findings confirm theoretical results, based on consideration of the roles of the buoyancy force, hydrodynamic force, and settling velocity, presented by Burr et al. (2006). Note, however, that the conclusions of Burr et al. (2006) were made for the same velocity, while we consider the same total discharge.

\section{CONCLUSIONS}

The main conclusions of this research are as follows:

- The simulations give realistic results for flow, transport, and sedimentation for terrestrial and Titan's rivers. Therefore, we have concluded that the use of the modelling package CCHE2D for extra-terrestrial rivers is fully justified;

- Three different liquid hydrocarbons considered for Titan's rivers give similar velocity fields;

- For the conditions considered in our research, the evolution of a terrestrial river leads to a quasi-braided river, while for
Titan we still have a typical meandering river for the entire simulation;

- The rate of sedimentation on Titan is higher than on Earth. The layers of new sediment on Titan have thicknesses of $10-40 \mathrm{~cm}$. For terrestrial conditions, the rate of sedimentation is much lower and subsequent layers are thinner $(\sim 5 \mathrm{~cm})$;

- The bed change averaged over a considered river channel for Titan is higher than for Earth. This is a result of a greater rate of transport of material on Titan;

- Suspended load is the main way of transport in Titan's simulated rivers. For Earth, the behaviour of the considered ratio is more complicated. The suspended load $S_{\text {mod }}$ could be of the same importance as the bedload, lower, or significantly higher, but not higher than $\sim 100 \mathrm{~B}$. The bedload transport rate is also much greater on Earth than on Titan; the maximal value is around $0.3 \mathrm{~kg} \cdot \mathrm{m}^{-1} \cdot \mathrm{s}^{-1}$ on Earth and negligible on Titan;

- Consideration of the stability of D50 particle distribution of bed sediments indicates that models for Titan's river require a longer time of simulation than for terrestrial rivers. This could be a result of low bedload on Titan and low significance of suspended load for erosion of the bed;

- Most of the results of our models could be explained theoretically, considering different values of gravity, density and viscosity of fluids, density of sediments, and different buoyancy forces for Titan and Earth.

Our investigations indicate substantial differences in the evolution of terrestrial river valleys compared to the evolution of similar sized valleys on Titan. The differences are the results of different rates of erosion, transport, and sedimentation. A better understanding of these processes requires further numerical simulations, experimental investigations, and more observational data from space missions. Moreover, detailed comparisons with analogous terrestrial processes could be helpful in determining the conditions necessary for forming braided or meandering rivers. A better understanding of these conditions will give scientists an important tool to interpret data from spacecraft and to explain the evolution of rivers on Titan. Note that the observational data for Titan are (and will be) mainly of the remote type (radar data, pictures made from orbiters rather than in-situ geological survey). Therefore, the development of special methods for interpretation is necessary. Detailed investigation of the differences between terrestrial rivers, turbidity currents, and Martian rivers could be important.

Acknowledgements. Programs developed by NCCHE are used in the research. The research is also partly supported by National Science Center (grant 2011/01/B/ST10/06653). The authors would like to thank the reviewers: Dr. N. Zalewska from the Space Research Center in Warsaw, Dr. A. Kereszturi from the Research Center for Astronomy and Earth Sciences, Konkoly Thege Miklos Astronomical Institute in Budapest and an anonymous reviewer one for their remarks and valuable comments. We are also grateful to Professor D. Burr from Department of Earth and Planetary Sciences at the University of Tennessee and Professor UW dr. hab. A. Wysocka from the Faculty of Geology at the University of Warsaw. 


\section{REFERENCES}

Abad, J.D., Sequeiros, O., Spinewine, B., Pirmez, C., Garcia, M., Parker, G., 2010. Secondary flow in meandering channels on submarine fans: implications for channel morphodynamics and architecture. Search and Discovery Article, 40480: 1-43.

Arcement, G., Schneider, V., 2013. Guide for Selecting Manning's Roughness Coefficients for Natural Channels and Flood Plains. United States Geological Survey Water-supply; http://www.fhwa.dot.gov/bridge/wsp2339.pdf

Atreya, S.K., Lorenz, R.D., Waite, J.H., 2009. Volatile origin and cycles: nitrogen and methane. In: Titan from Cassini-Huygens (eds. R.H. Brown, J. Lebreton and J.H. Waite): 177-199. Springer, Dordrecht.

Baker, V.R., Kochel, R.C., 1979. Martian channel morphology Maja and Kasei Valles. Journal of Geophysical Research, 84: 7961-7983.

Barnes, J.W., Radebaugh, J., Brown, R.H., Wall, S., Soderblom, L., Lunine, J., Burr, D., Sotin, Ch., Le Mouelic, S., Rodriguez, S., Buratti, B.J., Clark, R., Baines, K.H., Jaumann, R., Nicholson, P.D., Kirk, R.L., Lopes, R., Lorenz, R.D., Mitchell, K., Wood, Ch.A., 2007. Near-infrared spectral mapping of Titan's mountains and channels. Journal of Geophysical Research, 112: E11006.

Burr, D., Emery, J., Lorenz, R., Collins, G., Carling, P., 2006. Sediment transport by liquid surficial flow: application to Titan. Icarus, 181: 235-242.

Burr, D.M., Perron, J.T., Lamb, M.P., Irwin III, R.P., Collins, G.C., Howard, A.D., Sklar, L.S., Moore, J.M., Adamkovics, M., Baker, V.R., Drummond, S.A., Black, B.A., 2013a. Fluvial features on Titan: Insights from morphology and modeling. GSA Bulletin, 125: 299-321.

Burr, D.M., Drummond, S.A., Cartwright, R., Black, B.A., Perron, J.T., 2013b. Morphology of fluvial networks on Titan: evidence for structural control. Icarus, 226: 742-759.

Carr, M.H., Clow, G.D., 1981. Martian channels and valleys - their characteristics, distribution, and age. Icarus, 48: 91-117.

Cordier, D., Mousis, O., Lunine, J.I., Lavvas, P., Vuitton, V., 2009. An estimate of the chemical composition of Titan's lakes. The Astrophysical Journal, 707: L128-L131.

Cornet, T., Bourgeois, O., Mouélic, S.L., Rodriguez, S., Gonzalez, T.L., Sotin, C., Tobie, G., Fleurant, C., Barnes, J.W., Brown, R.H., Baines, K.H., Buratti, B.J., Clark, R.N., Nicholson, P.D., 2012. Geomorphological significance of Ontario Lacus on Titan: integrated interpretation of Cassini VIMS, ISS and RADAR data and comparison with the Etosha Pan (Namibia). Icarus, doi: 10.1016/j.icarus.2012.01.013

Craddock, R.A., Maxwell, T.A., 1993. Geomorphic evolution of the Martian highlands through ancient fluvial processes. Journal of Geophysical Research, 98: 3453-3468.

Czechowski, L., Kossacki, K., 2009. Thermal convection in the porous methane-soaked regolith in Titan: investigation of stability. Icarus, 202: 599-607.

Czechowski, L., Kossacki, K., 2012. Thermal convection in the porous methane-soaked regolith in Titan: finite amplitude convection. Icarus, 217: 130-143.

Elachi, C., Wall, S., Allison, M., Anderson, Y., Boehmer, R., Callahan, P., Flamini, E., Franceschetti, G., Gim, Y., Hamilton, G., Hensley, S., Janssen, M., Johnson, W., Kelleher, K., Kirk, R., Lopes, R., Lorenz, R., Lunine, J., Muhleman, D., Ostro, S., Paganelli, F., Picardi, G., Posa, F., Roth, L., Seu, R., Shaffer, S., Soderblom, L., Stiles, B., Stofan, E., Vetrella, S., West, R., Wood, C., Wye, L., Zebker, H., 2005. Cassini Radar views the surface of Titan. Science, 308: 970-974.

Frenzen, P., Vogel, Ch., 1994. On the Magnitude and Apparent Range of Variation of the von Karman Constant in the Atmospheric Surface Layer. Boundary-Layer Meteorology.

Griffith, C., Hall, J., Geballe, T., 2000. Detection of daily clouds on Titan. Science, 290: 509-513.

Hayes, A., Aharonson, O., Callahan, P., Elachi, C., Gim, Y., Kirk, R., Lewis, K., Lopes, R., Lorenz, R., Lunine, J., Mitchell, K.,
Mitri, G., Stofan, E., Wall, S., 2008. Hydrocarbon lakes on Titan: distribution and interaction with a porous regolith. Geophysical Research Letters, 35: L09204

Hulme, G., 1973. Turbulent lava flow and the formation of lunar sinuous rilles. Modern Geology, 4: 107-117.

Jaromin, K., Jlilati, A., Borkowski, T., Widmoski, M., Łagód, G., 2008. Rodzaje materiału i sposoby eksploatacji a współczynnik szorstkości w przewodach kanalizacji grawitacyjnej (in Polish). Proceedings of ECOpole, Lublin.

Jaumann, R., Brown, R.H., Stephan, K., Barnes, J.W., Soderblom, L.A., Sotin, Ch., Le Mouelic, S., Clark, R.N., Soderblom, J., Buratti, B.J., Wagner, R., Mccord, T.B., Rodirguez, S., Bains, K.H., Cruikshank, D.P., Nicholson, P.D., Griffith, C.A., Langhans, M., Lorenz, R.D., 2008. Fluvial erosion and post-erosional processes on Titan. Icarus, 197: 526-538.

Jia, Y., Wang, S., 2001. CCHE2D: two-dimensional Hydrodynamic and Sediment Transport Model For Unsteady Open Channel Flow Over Loose Bed. Technical Report No. NCCHETR-2001-1.

Kereszturi, A., 2003. Paleodischarge Estimation from Morphometry for Ancient Channels. 6th International Conference on Mars, abstract 3039.

Kereszturi, A., 2005. Cross-sectional and longitudinal profiles of valleys and channels in Xanthe Terra on Mars. Journal of Geophysical Research, 110 (E12), CitelD E12S17.

Kereszturi, A., 2010. Lakes beyond the Earth: dry lakebeds on Mars, and active methane-ethane lakes on Titan. In: Ponds Formation, Characteristics, and Uses (ed. Paul L. Meyer): 125-138. Nova Publisher.

Langhans, M.H., Jaumann, R., Stephan, K., Brown, R.H., Buratti, B.J., Clark, R.N., Bains, K.H., Nicholson, P.D., Lorenz, R.D., Soderblom, J.M., Sotin, C., Barnes, J.W., Nelson, R., 2012. Titan's fluvial valleys: Morphology, distribution, and spectral properties. Planetary and Space Science, 60: 34-51.

LeGall, A., Janssen, M.A., Paillou, P., Lorenz, R.D., Wall, S.D., the Cassini Radar Team, 2010. Radar-bright channels on Titan. Icarus, 207: 948-958.

Leopold, L.B., Emmett, W.W., 1976. Bedload measurements, East Fork River, Wyoming, Proceedings. National Academy of Sciences, 73: 1000-1004.

Litwin, K.L., Zygielbaum, B.R., Polito, P.J., Sklar, L.S., Collins, G.C., 2012. Influence of temperature, composition and grain size on the tensile failure of water ice: implications for erosion on Titan. Journal of Geophysical Research - Planets, 117: E08013.

Lopes, R.M.C., Stofan, E.R., Peckyno, R., Radebaugh, J., Mitchell, K.L., Mitri, G., Wood, C.A., Kirk, R.L., Wall, S.D., Lunine, J.I., Hayes, A., Lorenz, R., Farr, T., Wye, L., Craig, J., Ollerenshaw, R.J., Janssen, M., LeGall, A., Paganelli, F., West, R., Stiles, B., Callahan, P., Anderson, Y., Valora, P., Soderblom, L., the Cassini RADAR Team, 2010. Distribution and interplay of geologic processes on Titan from Cassini radar data. Icarus, 205: 540-558.

Lorenz, R.D., Biolluz, G., Encrenaz, P., Janssen, M.A., West, R.D., Muhleman, D.O., 2003. Cassini RADAR: prospects for Titan surface investigations using the microwave radiometer. Planetary and Space Science, 51: 353-364.

Lorenz, R.D., Lopes, R.M., Paganelli, F., Lunine, J.I., Kirk, R.L., Mitchell, K.L., Soderblom, L.A., Stofan, E.R., Ori, G., Myers, M., Miyamoto, H., Radebaugh, J., Stiles, B., Wall, S.D., Wood, C.A., the Cassini RADAR Team, 2008. Fluvial channels on Titan: initial Cassini RADAR observations. Planetary and Space Science, 56: 1132-1144.

Lorenz, R.D., Newman, C., Lunine, J.I., 2010. Threshold of wave generation on Titan's lakes and seas: effect of viscosity and implications for Cassini observations. Icarus, 207: 932-937.

Lunine, J.I., Atreya, S.K., 2008. The methane cycle on Titan. Nature Geoscience, 1: 159-164.

Lunine, J., Lorenz, R., 2009. Rivers, lake, dunes and rain: crustal processes in Titan's methane cycle. AREPS, 37: 299-320. 
Magnuszewski, A., Gutry-Korycka, M., 2009a. Reconstruction of the Vistula River extreme floods passage through the city of Warsaw in natural river conditions. Prace i Studia Geograficzne, 43: 141-151.

Magnuszewski, A., Gutry-Korycka, M., 2009b. Flood waters flow in the contemporary Vistula River channel. Prace i Studia Geograficzne, 43: 153-162.

Misiura, K., Czechowski, L., 2013. Comparison of sedimentary processes in rivers of Titan and the Earth. EPSC Abstracts, 8: EPSC2013-554.

Mitri, G., Showman, A.P., Lunine, J.I., Lorenz, R.D., 2007. Hydrocarbon lakes on Titan. Icarus, 186: 385-394.

Moore, J.M., Howard, A.D., 2010. Are the basins of Titan's Hotei Regio and Tui Regio sites of former low latitude seas? Geophysical Research Letters, 37: L22205.

Nichols, G., 1999. Sedimentology and Stratigraphy. Wiley-Blackwell, Oxford

Perron, J.T., Lamb, M.P., Koven, C.D., Fung, I.Y., Yager, E., Adámkovics, M., 2006. Valley formation on Titan. Journal of Geophysical Research, 111: E11001.

Schumm, S.A., 1981. Evolution and response of the fluvial system, sedimentologic implications. SEPM, Special Publication, 1: 19-29.

Sequeiros, O., Spinewine, B., Beaubouef, R., Sun, T., Savoye, B., Garcia, M., Parker, G., 2010. Controls on gravel deposits in deep-water reservoirs; bedload transport and bedforms associated with turbidity currents. Search and Discovery Article 40516 http://www.searchanddiscovery.com/documents/2010/40516sequeiros/ndx_sequeiros.pdf

Soderblom, L.A., Tomasko, M.G., Archinal, B.A., Becker, T.L., Bushroe, M.W., Cook, D.A., Doose, L.R., Galuszka, D.M., Hare, T.M., Howington-Kraus, E., Karkoschka, E., Kirk, R.L., Lunine, J.I., McFarlane, E.A., Redding, B.L., Rizk, B., Rosiek, M.R., See, Ch., Smith, P.H., 2007. Topography and geomorphology of the Huygens landing site on Titan. Planetary and Space Science, 55: 2015-2024.
Strobel, D.F., Atreya, S.K., Bézard, B., Ferri, F., Flasar, F.M., Fulchignoni, M., Lellouch, E., Muller-Wodarg, I., 2009. Atmospheric structure and composition. In: Titan from Cassini-Huygens (eds. R.H. Brown, J. Lebreton and J.H. Waite): 235-257. Springer, Dordrecht.

Tomasko, M.G., Archinal, B., Becker, T., Bézard, B., Bushroe, M., Combes, M., Cook, D., Coustenis, A., de Bergh, C., Dafoe, L.E., Doose, L., Douté, S., Eibl, A., Engel, S., Gliem, F., Grieger, B., Holso, K., Howington-Kraus, E., Karkoschka, E., Keller, H.U., Kirk, R., Kramm, R., Küppers, M., Lanagan, P., Lellouch, E., Lemmon, M., Lunine, J., McFarlane, E., Moores, J., Prout, G.M., Rizk, B., Rosiek, M., Rueffer, P., Schröder, S.E., Schmitt, B., See, C., Smith, P., Soderblom, L., Thomas, N., West, R., 2005. Rain, winds and haze during the Huygens probe's descent to Titan's surface. Nature, 438: 765-778.

Turtle, E.P., Perry, J.E., Hayes, A.G., McEwan, A.S., 2011 a. Shoreline retreat at Titan's Ontario Lacus and Arrakis Planitia from Cassini imaging science subsystem observations. Icarus, 212: 957-959.

Turtle, E.P., Perry, J.E., Hayes, A.G., Lorenz, R.D., Barnes, J.W., McEwen, A.S., West, R.A., Del Genio, A.D., Barbara, J.M., Lunine, J.I., Schaller, E.L., Ray, T.L., Lopes, R.M.C., Stofan, E.R., 2011b. Rapid and extensive surface changes near Titan's equator: evidence of April showers. Science, 331: 1414-1417.

Witek, P.P., Czechowski, L., 2013. Fluvial deposition processes on Titan - origin and evolution of landforms. EPSC Abstracts, 8: EPSC2013-365.

Witek, P.P., Czechowski, L., 2015. Dynamical modelling of river deltas on Titan and Earth. Planetary and Space Science, 105: 65-79.

Wu, W., 2001. CCHE2D Sediment Transport Model (Version 2.1). Technical Report No. NCCHE-TR-2001-3.

Zhang, Y., 2006. CCHE-GUI - Graphical Users Interface for NCCHE Model User's Manual - Version 3.0. Technical Report No. NCCHE-TR-2006-02. 